\title{
Launch and Assembly Reliability Analysis for Mars Human Space Exploration Missions
}

\author{
Grant Cates \\ Science Applications International \\ Corporation \\ 8910 Astronaut Boulevard, Suite 330 \\ Cape Canaveral, FL 32920 \\ 321-867-7820 / 703-676-8246 \\ grant.r.cates@saic.com
}

\author{
Chel Stromgren \\ Binera, Inc. \\ 912 Thayer Avenue, Suite 209 \\ Silver Spring, MD 20910 \\ 301-686-8571 \\ c.stromgren@binera.com
}

\author{
William Cirillo / Kandyce Goodliff \\ NASA Langley Research Center \\ 1 North Dryden Street \\ Hampton, VA 23681 \\ 757-864-1938 / 757-864-4969 \\ william.m.cirillo@nasa.gov / \\ kandyce.e.goodliff@nasa.gov
}

\begin{abstract}
NASA's long-range goal is focused upon human exploration of Mars. Missions to Mars will require campaigns of multiple launches to assemble Mars Transfer Vehicles in Earth orbit. Launch campaigns are subject to delays, launch vehicles can fail to place their payloads into the required orbit, and spacecraft may fail during the assembly process or while loitering prior to the Trans-Mars Injection (TMI) burn. Additionally, missions to Mars have constrained departure windows lasting approximately sixty days that repeat approximately every two years. Ensuring high reliability of launching and assembling all required elements in time to support the TMI window will be a key enabler to mission success. This paper describes an integrated methodology for analyzing and improving the reliability of the launch and assembly campaign phase. A discrete event simulation involves several pertinent risk factors including, but not limited to: manufacturing completion; transportation; ground processing; launch countdown; ascent; rendezvous and docking, assembly, and orbital operations leading up to TMI. The model accommodates varying numbers of launches, including the potential for spare launches. Having a spare launch capability provides significant improvement to mission success.
\end{abstract}

\section{TABLE OF CONTENTS}

1. INTRODUCTION .1

2. COMPLEXITY AND RISKS OF LAUNCH AND

ASSEMBLY .2

3. CONCEPT OF OPERATION FOR MARS HUMAN

EXPLORATION (DRA 5.0)

4. DESCRIPTION OF SIMULATION MODEL ...........6

5. DESCRIPTION OF CASES ANALYZED ..............11

6. RESULTS....................................................11

7. CONCLUSIONS AND FORWARD WORK ...........14

REFERENCES...................................................15

BIOGRAPHIES.........................................................16

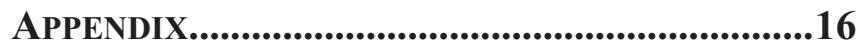

\section{INTRODUCTION}

NASA has been analyzing strategies for human exploration of Mars for many years. In 2009, NASA published "Human Exploration of Mars: Design Reference Architecture 5.0" (DRA 5.0) [1] along with a detailed technical addendum [2] that describe an operations concept for the first human missions to Mars. The Mars DRA 5.0 documents represent the most comprehensive study for human exploration of Mars published to date and now serve as the point of departure for continued studies.

There have been several key strategic changes since the 2009 timeframe that are being factored into current analyses. Changes to NASA's human exploration program since 2009 include: the cancellation of the Ares I launch vehicle; the replacement of the planned Ares V launch vehicle with the Space Launch System (SLS); and changes to the ground processing architecture. These changes have significant ramifications to the launch and assembly phase of missions to Mars.

Remaining unchanged is the complex nature of Mars exploration, especially the reliability of launching and assembling all the required elements in a timely manner to support the planned departure window. To assist in the reliability analysis, NASA has been developing an integrated methodology to analyze launch and assembly reliability. This work builds upon previous analyses performed for the Space Shuttle and International Space Station Programs $[3,4,5]$, the Constellation Program [6, 7], the Review of Human Space Flight Plans Committee [8], and studies performed in 2011 on launch and assembly reliability for human exploration missions to near-Earth asteroids [9].

The integrated launch and assembly reliability methodology starts with flight hardware manufacturing and ends with final departure of a Mars Transfer Vehicle (MTV) or set of MTVs from the Earth assembly orbit. Pertinent risk factors are accounted for within a stochastic discrete event simulation for each Design Reference Mission (DRM).

This paper presents illustrative results from analysis of the launch and assembly campaigns described in DRA 5.0 (modified to reflect NASA's programmatic changes since that time, as described above) and suggests ways in which reliability can be significantly improved. Section 2 introduces the complexities and risks inherent to launch and assembly of Mars missions. Section 3 provides a brief overview of the concept of operations considered by DRA 5.0. The fourth section describes the simulation models. Section 5 lists the cases analyzed followed by the results in 
Section 6. Conclusions and forward work are addressed in Section 7.

\section{COMPLEXITY AND RISKS OF LAUNCH AND ASSEMBLY}

The DRA 5.0 concept for human exploration of Mars requires multiple launches to assemble multiple Mars Transfer Vehicles (MTVs) in Earth orbit. The process of completing all of the required launches and assembly activities will be complex and require significant time. The launch and assembly activities need to be planned with sufficient margin such that they can be reliably completed prior to the desired departure window. If the window of opportunity for MTV departure-which is assumed to be open for approximately 60 days-is missed, spacecraft already in Earth orbit will likely not be mission capable 26 months later, at the next departure opportunity.

\section{Key Constraints}

Human exploration missions to Mars have several constraints that will directly impact the launch and assembly reliability. Constraints in addition to the limited departure opportunities include: the reliability of the Space Launch System (SLS), the amount of cargo up-mass and volume provided by the SLS; the reliability and on-orbit lifetime capacity of the elements being placed in Earth orbit; and the ground processing architecture and workforce for preparing launch vehicles and their respective payload elements.

Minimum energy departure opportunities to Mars are available from an assumed low Earth orbit (LEO) assembly orbit for an assumed period of 60 days every 26 months. The actual duration of the departure window may be different depending upon the delta velocity capacity of future MTVs.

NASA is presently planning to build a SLS capable of placing 105 metric tons (t) into LEO and may ultimately increase this capacity to $130 \mathrm{t}$. The mass and volumetric capacity of the SLS will influence how many launches need to be conducted for any given scenario. Fewer launches should be better than more launches, however differences in reliability are also considered in the analysis methodology for optimizing the overall probability of launch and assembly success.

During the time that Mars DRA 5.0 was developed, NASA was planning on a robust ground processing architecture that made use of multiple launch vehicle integration high bays in the Vehicle Assembly Building (VAB) at the Kennedy Space Center along with multiple mobile launchers and two launch pads. Since that time, NASA has scaled back the plans such that only a "single-string" capacity is being put in place. This means that there will only be one mobile launcher, one launch pad and one launch vehicle integration high bay. This concept essentially precludes parallel processing of multiple launch vehicles.
In DRA 5.0, launches were planned to occur on 30-day centers. The planned single string architecture, along with planned processing on a 5 day - two 8-hour shifts per day $(5 \times 2)$, precludes this frequency of launches. Analysis point of departure begins with the planned single string architecture with $5 \times 2$ processing but also utilizes alternative assumptions, e.g., a dual string architecture with $5 \times 3$ processing ( 5 day, 24 hour processing).

Launch reliability could be improved by adding time margin to the launch and assembly schedule. If launches for all elements and the crew were planned to occur earlier, relative to the destination departure window, the probability of completing all of the required activities in time to meet the departure opportunity increases significantly. DRA 5.0 acknowledged this fact by concluding that approximately 90-180 days of margin would be inserted in the launch campaign plan between the last launch of the campaign and the opening of the Earth departure window.

However, given the complexity of the launch and assembly campaign and the many delay risks, it is not clear that 90180 days will be adequate. Unfortunately, there are also additional constraints that limit the ability to add time margin to the launch and assembly schedule.

Increasing the amount of time that elements of the MTVs loiter in the assembly orbit adds additional risk to the assembly process. The probability of system failures within the elements or of micrometeorite and orbital debris (MMOD) strikes increase as loiter time is extended. In addition, adding margin will increase the total lifetime of elements. Leaving elements in space for longer durations prior to departure could increase the risk of failure later in the mission, during more critical stages.

Crew time in space is also a major issue with adding margin to the launch and assembly process. Because the crew launch is typically the last launch in the sequence, adding margin between that event and the departure window will have the greatest benefit on reliability. However, there are significant issues to adding to the amount of time that crew must spend in space. The expected Mars mission time is approximately 2.5 years and already presents challenges to the crew. Requiring the crew to loiter at the assembly point prior to departure will only increase those risks. Additional time loitering at the assembly location also increases the risk that a crew health event will occur, requiring an abort back to Earth and thus ending the mission.

In order to commit to a human mission to Mars, all of these constraints as well as the many risks identified below will have to be addressed such that there is an acceptably high level of confidence that the launch and assembly will be successful. 


\section{Types of Risks}

The types of risks involved in the launch and assembly of the MTVs can be divided into two major categories: PreLaunch Risks and Post-Launch Risks.

Pre-Launch Risks are those that occur prior to ignition of the main engines of the launch vehicle for any launch that supports the mission. These risks involve all of the activities required to manufacture, deliver, assemble, and prepare each vehicle for launch.

Manufacturing Reliability-All elements for the Mars mission, including MTVs elements, launch vehicles, and propulsive elements must be manufactured, tested, and delivered to the space center. Delays in these activities would delay the launch and assembly schedule. The risk of manufacturing related delays was quantified using Space Shuttle historical data

Processing Reliability-Processing capabilities at the space center are limited by facilities and personnel constraints. These constraints dictate the planned launch schedule for elements. Delays in completing element processing and launch vehicle assembly could significantly impact the launch and assembly schedule.

Launch Reliability - The launch of spacecraft in Earth orbit is notoriously unreliable. Historically, the success rate for launching a spacecraft on any specific attempt has been a little above 50\%. The Space Shuttle launch probability throughout its history was 0.53 . Even the relatively simple Delta II only had a 0.56 launch probability for launches between 1989 and 2001 [10]. While many delays are weather related or involve minor problems that can be quickly corrected, either of which allow the next attempt to occur quickly, there are often failures on the launch pad that require long periods of time to correct. In addition, because of limited launch windows required to conduct on-orbit rendezvous, even small delays may cause launch to be delayed for a minimum of 24 hours. Conducting multiple launches to support a Mars mission increases the exposure to launch delays, potentially reducing the overall probability of meeting the departure window.

Post-Launch Risks are those that occur after the ignition of the main engines of the launch vehicle and involve all of the activities required to position and assemble elements, deliver the crew to the MTVs, and prepare for departure.

Launch Failure-The launch and ascent of a vehicle into LEO is typically one of the most risky phases in any space mission. Conducting multiple launches into LEO to support the mission will increase the overall probability of launch failure in at least one of the launches.

Element Failure on Orbit-As elements loiter in LEO or at some other potential spacecraft assembly point, there are multiple types of failure that can occur that could endanger the mission. Potential failures include unrepairable system failures within the spacecraft elements, MMOD strikes on spacecraft elements, and damage due to radiation exposure. These risks increase as loiter period increases.

Propulsive Failure - Subsequent to launch into LEO, many missions will require elements to be relocated to the spacecraft assembly location. This will require some form of in-space propulsion. Failure or delays with these events could result in failure of the overall mission. Elements also require on-going station keeping. Failure of the Reaction Control System (RCS) could also result in mission failure.

Assembly/Docking Failure-Assembly of the MTVs will require that multiple independently launched elements be aggregated in space. That will require some form of rendezvous and docking of those elements. Because the crew will likely not be present when most of the assembly events occur, the assembly will involve automated rendezvous and docking (ARD) events. Historically, ARD has proved troublesome for in-space vehicles and a number of failures have occurred. Failure in the assembly of the MTVs could result in failure of the overall mission.

Crew Issues-Problems with the crew, including health issues and injury, can occur as the crew travels to the assembly location, and/or loiters in the MTVs prior to departure. Serious crew issues could require abort back to Earth and abandonment of the mission.

Departure Burn Failures-A primary purpose of the Mars Transfer Vehicle is to perform the propulsion burn required to escape Earth orbit. The potential for failure at this point is a function of the reliability of the propulsion system. That reliability risk needs to take into consideration that the propulsion system will have been loitering in Earth orbit for an extended duration of time, potentially a year or more. Today's upper stages used to propel spacecraft beyond Earth orbit are typically fired within minutes or hours of launch. Departure burn failures, while resulting in a loss of mission, would still allow the crew to abort back to Earth.

The constraints and risks described herein require that missions be designed in a way that the total achieved launch and assembly reliability will result in an acceptable probability of mission success. The reliability and the timing of launch and assembly events must be carefully evaluated in order to identify and mitigate those risks.

There is a fundamental tension between adding margin to the launch schedule and the amount of in-space risk exposure. A balance must be achieved between these factors in order to develop an acceptable level of overall reliability.

This evaluation should occur in conjunction with the analysis and design of the launch systems and MTV elements. Because most of these systems and many of the technologies that are incorporated into them do not yet exist, it is still possible to influence capabilities and system reliabilities in order to achieve a reasonable overall reliability. 


\section{CONCEPT OF OPERATION FOR MARS HUMAN EXPLORATION (DRA 5.0)}

The basic concept of operations described in Mars DRA 5.0 was to send three Mars Transfer Vehicles (MTVs) to Mars as shown in Figure 1 [1]. Each of the three MTVs would propel one of the three major payload elements required at Mars to conduct the mission. These were: (1) a Mars surface habitat (the SHAB) that the crew uses to descend to the Mars surface and where they live in and work from during their stay on Mars; (2) a Mars descent / ascent vehicle (the MDAV) that is used to descend exploration gear to the Mars surface and then at the conclusion of the Mars surface mission to ascend the crew back to Mars orbit; and (3) the deep space habitat (the $\mathrm{HAB}$ ) that the crew would live in during their transit from Earth orbit to Mars orbit and back.

Mars DRA 5.0 considered two propulsion concepts for the MTVs, Nuclear Thermal Rocket (NTR) or Chemical. It also considered two alternatives for getting the three MTV payloads to Mars, either "all-up" or "pre-deployed." In the example depicted in Figure 1 the SHAB and MDAV were "pre-deployed" in that they were sent to Mars 26 months prior to departure of the crew from Earth orbit. Other concepts known as "all-up" sent all three MTVs to Mars during one Mars departure window opportunity.

For DRA 5.0 the total amount of up-mass required to LEO was dependent upon: (1) the type of propulsion used by the MTV with NTR requiring less mass than chemical propulsion and; (2) the strategy for going to Mars, i.e., "predeployed" versus "all-up", which requires more mass. According to DRA 5.0 documentation, the pre-deployed missions require less mass because the cargo missions are sent on more energy efficient trajectories thus requiring less propellant for the same surface system mass. Figure 2 [2] shows the DRA 5.0 assessment of up-mass required to LEO for the various alternatives.

Using the information from Mars DRA 5.0 depicted in Figure 2 and the capacity of the SLS, either 105 t or $130 \mathrm{t}$, Table 1 was created to identify the number of SLS launches required for the representative scenarios analyzed. There was no optimization of elements and launch vehicles performed to align the number of launches required. The number of launches is an approximate representation and further in-depth analysis would be required to verify these numbers and assumptions.

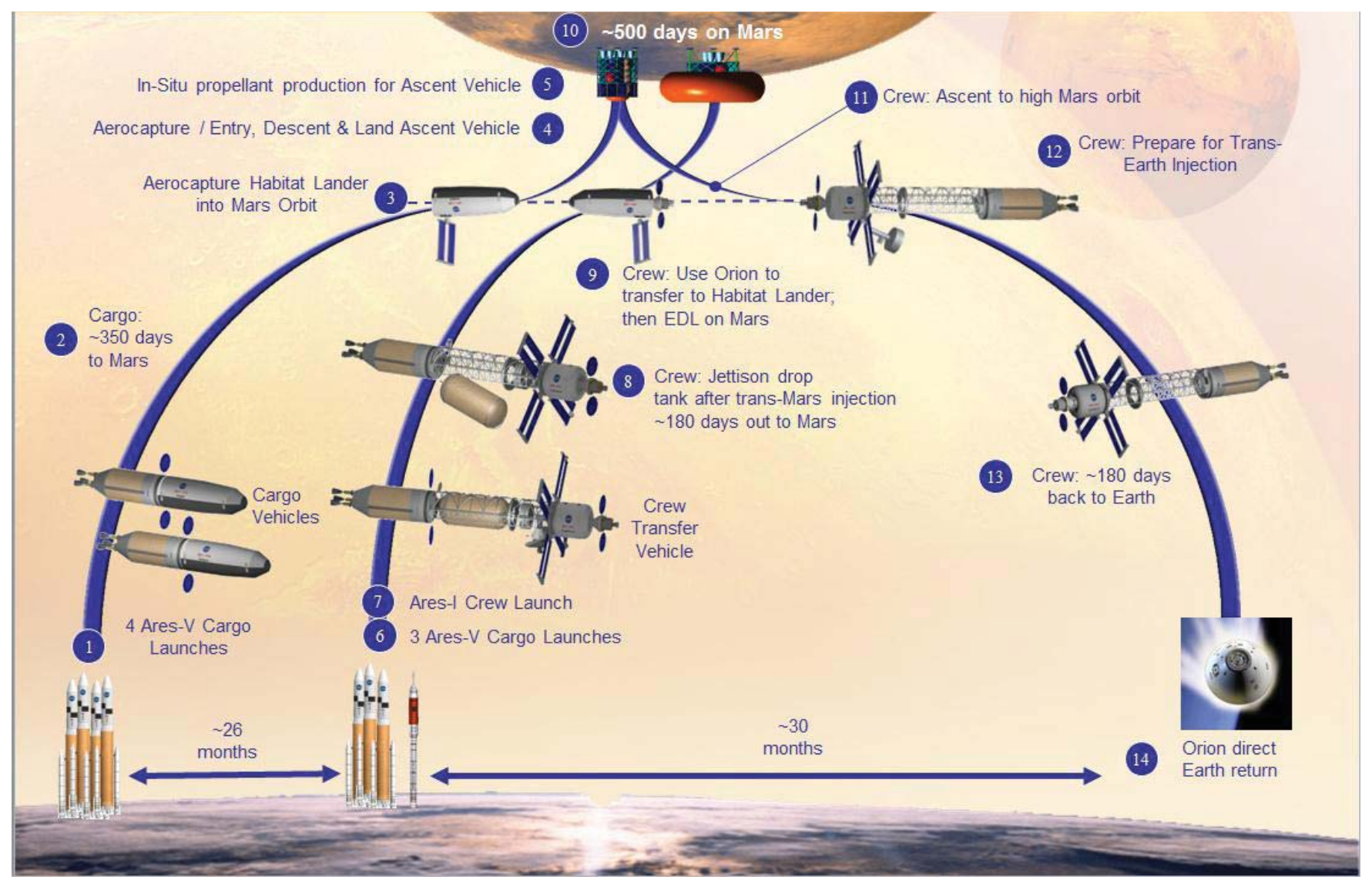

Figure 1 - Example Concept of Operations from Mars DRA 5.0 - "Pre-deployed" \& NTR 


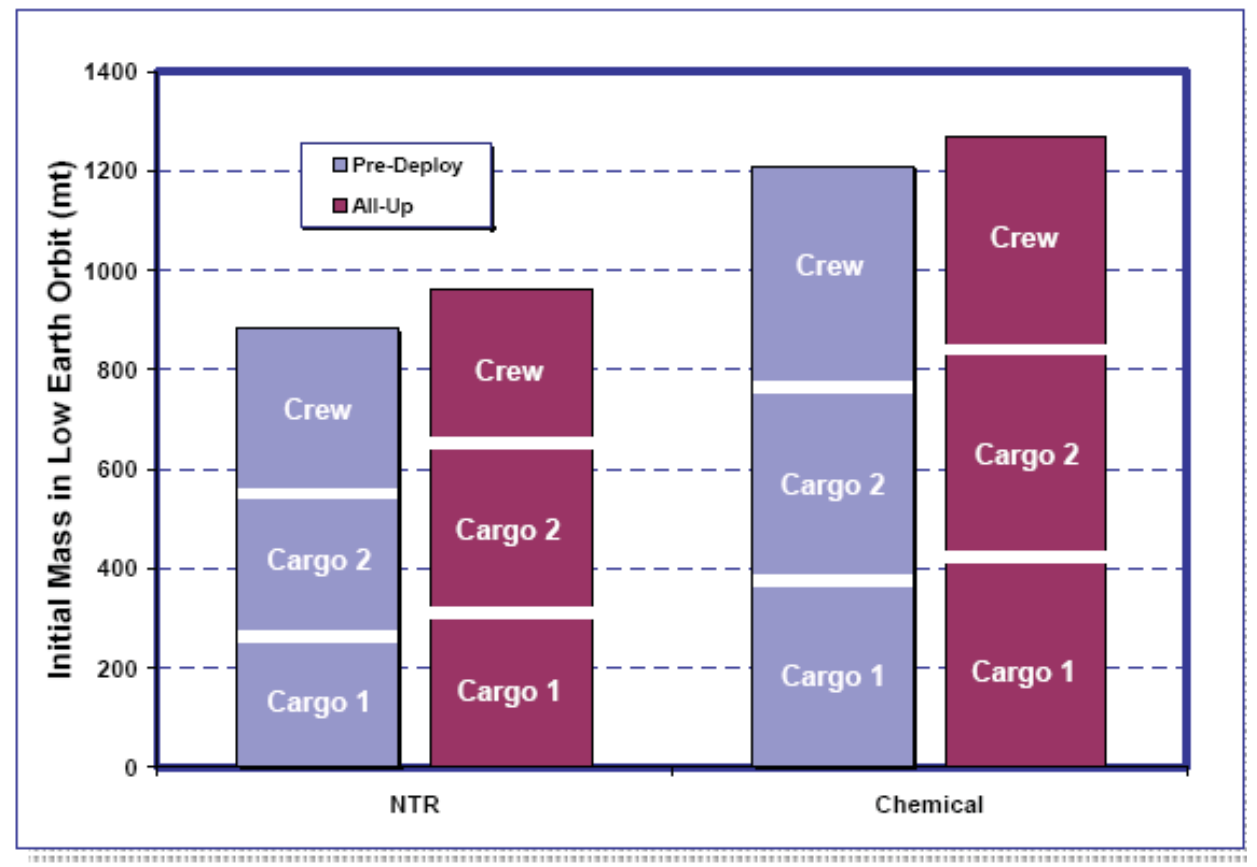

Figure 2 - Up-Mass to LEO from Mars DRA 5.0

Table 1. Assessment for Number of SLS Launches Required per MTV

\begin{tabular}{|c|c|c|c|c|c|c|c|c|}
\hline SLS Up-Mass Capacity & \multicolumn{4}{|c|}{105 t Capable SLS } & \multicolumn{4}{|c|}{130 t Capable SLS } \\
\hline MTV Propulsion Type & \multicolumn{2}{|c|}{ NTR } & \multicolumn{2}{|c|}{ Chemical } & \multicolumn{2}{|c|}{ NTR } & \multicolumn{2}{|c|}{ Chemical } \\
\hline Deployement Strategy & Pre-Deploy & All-Up & Pre-Deploy & All-Up & Pre-Deploy & All-Up & Pre-Deploy & All-Up \\
\hline \multirow{4}{*}{$\begin{array}{c}\text { MTV-1 } \\
\text { Payload } \\
\text { (Mars Descent / } \\
\text { Ascent Vehicle) }\end{array}$} & & & $\begin{array}{l}\text { Chem. Prop. } \\
\text { Module }\end{array}$ & $\begin{array}{c}\text { Chem. Prop. } \\
\text { Module }\end{array}$ & & & & $\begin{array}{l}\text { Chem. Prop. } \\
\text { Module }\end{array}$ \\
\hline & \begin{tabular}{|c|} 
Propellant Drop \\
Tank
\end{tabular} & \begin{tabular}{|c|} 
Propellant Drop \\
Tank
\end{tabular} & $\begin{array}{l}\text { Chem. Prop. } \\
\text { Module }\end{array}$ & $\begin{array}{l}\text { Chem. Prop. } \\
\text { Module }\end{array}$ & & \begin{tabular}{|c|} 
Propellant Drop \\
Tank
\end{tabular} & $\begin{array}{l}\text { Chem. Prop. } \\
\text { Module }\end{array}$ & $\begin{array}{l}\text { Chem. Prop. } \\
\text { Module }\end{array}$ \\
\hline & \begin{tabular}{|c|} 
NTR \\
Prop.Module \\
\end{tabular} & \begin{tabular}{|c|}
$\begin{array}{c}\text { NTR Prop. } \\
\text { Module }\end{array}$ \\
\end{tabular} & $\begin{array}{c}\text { Chem. Prop. } \\
\text { Module }\end{array}$ & $\begin{array}{c}\text { Chem. Prop. } \\
\text { Module }\end{array}$ & $\begin{array}{c}\text { NTR } \\
\text { Prop.Module }\end{array}$ & \begin{tabular}{|c|}
$\begin{array}{c}\text { NTR Prop. } \\
\text { Module }\end{array}$ \\
\end{tabular} & $\begin{array}{l}\text { Chem. Prop. } \\
\text { Module }\end{array}$ & $\begin{array}{c}\text { Chem. Prop. } \\
\text { Module }\end{array}$ \\
\hline & MDAV & MDAV & MDAV & MDAV & MDAV & MDAV & MDAV & MDAV \\
\hline \multirow{4}{*}{$\begin{array}{c}\text { MTV-2 } \\
\text { Payload } \\
\text { (Surface Habitat) }\end{array}$} & & \begin{tabular}{|c|} 
Propellant Drop \\
Tank
\end{tabular} & $\begin{array}{l}\text { Chem. Prop. } \\
\text { Module }\end{array}$ & $\begin{array}{c}\text { Chem. Prop. } \\
\text { Module }\end{array}$ & & & & $\begin{array}{c}\text { Chem. Prop. } \\
\text { Module }\end{array}$ \\
\hline & \begin{tabular}{|c|} 
Propellant Drop \\
Tank \\
\end{tabular} & \begin{tabular}{|c|} 
Propellant Drop \\
Tank \\
\end{tabular} & $\begin{array}{l}\text { Chem. Prop. } \\
\text { Module }\end{array}$ & $\begin{array}{c}\text { Chem. Prop. } \\
\text { Module }\end{array}$ & \begin{tabular}{|c|} 
Propellant Drop \\
Tank \\
\end{tabular} & $\begin{array}{c}\text { Propellant Drop } \\
\text { Tank }\end{array}$ & $\begin{array}{l}\text { Chem. Prop. } \\
\text { Module }\end{array}$ & $\begin{array}{c}\text { Chem. Prop. } \\
\text { Module }\end{array}$ \\
\hline & \begin{tabular}{|c|} 
NTR \\
Prop.Module \\
\end{tabular} & $\begin{array}{l}\text { NTR Prop. } \\
\text { Module }\end{array}$ & $\begin{array}{l}\text { Chem. Prop. } \\
\text { Module }\end{array}$ & $\begin{array}{l}\text { Chem. Prop. } \\
\text { Module }\end{array}$ & $\begin{array}{c}\text { NTR } \\
\text { Prop.Module } \\
\end{array}$ & $\begin{array}{l}\text { NTR Prop. } \\
\text { Module }\end{array}$ & $\begin{array}{c}\text { Chem. Prop. } \\
\text { Module }\end{array}$ & $\begin{array}{l}\text { Chem. Prop. } \\
\text { Module }\end{array}$ \\
\hline & SHAB & SHAB & SHAB & SHAB & SHAB & SHAB & SHAB & SHAB \\
\hline \multirow{5}{*}{$\begin{array}{c}\text { MTV-3 } \\
\text { Payload } \\
\text { (Deep Space Habitat) } \\
\text { and Crew-Orion } \\
\text { (always on } 105 \text { mT SLS }\end{array}$} & & & $\begin{array}{l}\text { Chem. Prop. } \\
\text { Module }\end{array}$ & $\begin{array}{c}\text { Chem. Prop. } \\
\text { Module }\end{array}$ & & & $\begin{array}{l}\text { Chem. Prop. } \\
\text { Module }\end{array}$ & \\
\hline & \begin{tabular}{|c|} 
Propellant Drop \\
Tank \\
\end{tabular} & \begin{tabular}{|c|} 
Propellant Drop \\
Tank \\
\end{tabular} & $\begin{array}{l}\text { Chem. Prop. } \\
\text { Module }\end{array}$ & $\begin{array}{l}\text { Chem. Prop. } \\
\text { Module }\end{array}$ & $\begin{array}{c}\text { Propellant Drop } \\
\text { Tank }\end{array}$ & \begin{tabular}{|c|} 
Propellant Drop \\
Tank
\end{tabular} & $\begin{array}{l}\text { Chem. Prop. } \\
\text { Module }\end{array}$ & $\begin{array}{c}\text { Chem. Prop. } \\
\text { Module }\end{array}$ \\
\hline & \begin{tabular}{|c|} 
NTR \\
Prop.Module \\
\end{tabular} & $\begin{array}{l}\text { NTR Prop. } \\
\text { Module }\end{array}$ & $\begin{array}{l}\text { Chem. Prop. } \\
\text { Module }\end{array}$ & $\begin{array}{c}\text { Chem. Prop. } \\
\text { Module }\end{array}$ & $\begin{array}{c}\text { NTR } \\
\text { Prop.Module } \\
\end{array}$ & $\begin{array}{l}\text { NTR Prop. } \\
\text { Module }\end{array}$ & $\begin{array}{l}\text { Chem. Prop. } \\
\text { Module }\end{array}$ & $\begin{array}{l}\text { Chem. Prop. } \\
\text { Module }\end{array}$ \\
\hline & HAB & $\mathrm{HAB}$ & HAB & HAB & HAB & HAB & HAB & HAB \\
\hline & $\begin{array}{l}\text { Crew- } \\
\text { Orion }\end{array}$ & $\begin{array}{l}\text { Crew- } \\
\text { Orion }\end{array}$ & $\begin{array}{l}\text { Crew- } \\
\text { Orion }\end{array}$ & $\begin{array}{l}\text { Crew- } \\
\text { Orion }\end{array}$ & $\begin{array}{l}\text { Crew- } \\
\text { Orion }\end{array}$ & $\begin{array}{l}\text { Crew- } \\
\text { Orion }\end{array}$ & $\begin{array}{l}\text { Crew- } \\
\text { Orion }\end{array}$ & $\begin{array}{l}\text { Crew- } \\
\text { Orion }\end{array}$ \\
\hline \multirow[t]{2}{*}{ Total SLS Launches } & 10 & 11 & 13 & 13 & 9 & 10 & 11 & 12 \\
\hline & \multicolumn{4}{|c|}{105 t Capable SLS } & \multicolumn{4}{|c|}{$130 \mathrm{t}$ Capable SLS } \\
\hline $\begin{array}{r}\text { Launches per Departure } \\
\text { Window Opportunity }\end{array}$ & $\begin{array}{c}\text { NTR } \\
\text { Pre-Deploy } \\
\end{array}$ & $\begin{array}{c}\text { NTR } \\
\text { All-Up }\end{array}$ & $\begin{array}{c}\text { Chemical Pre- } \\
\text { Deploy }\end{array}$ & $\begin{array}{l}\text { Chemical } \\
\text { All-Up }\end{array}$ & $\begin{array}{c}\text { NTR } \\
\text { Pre-Deploy }\end{array}$ & $\begin{array}{l}\text { NTR } \\
\text { All-Up }\end{array}$ & $\begin{array}{c}\text { Chemical Pre- } \\
\text { Deploy }\end{array}$ & $\begin{array}{l}\text { Chemical } \\
\text { All-Up }\end{array}$ \\
\hline MTV-1 \& 2 Pre-Deploy & 6 & & 8 & & 5 & & 6 & \\
\hline MTV-3 (if $1 \& 2$ predeployed) & 4 & & 5 & & 4 & & 5 & \\
\hline MTV's 1,2,\& 3 "all-up" & & 11 & & 13 & & 10 & & 12 \\
\hline
\end{tabular}




\section{Description of Simulation Model}

A stochastic discrete event simulation model was created using Rockwell Automation's Arena simulation software [11]. Figure 3 provides a high level overview of the model, which includes linkages to Excel files for inputs and results. The model logic includes entity routing to reflect all of the major processes and operations in the launch and assembly sequence from manufacturing completion through readiness and performance of the Earth departure burn, as shown in Figure 4.

The simulation is run for 1,000 replications, with each replication representing one possible manifestation of the launch and assembly sequence. The only difference between the replications is the random numbers used to drive the various risk models.

Analyst sets control variables in the Arena file including risk factor settings.-

Simulation logic implements all activities from manufacturing completion through departure window. Risk models provide opportunities for activities to be delayed or for elements to fail.

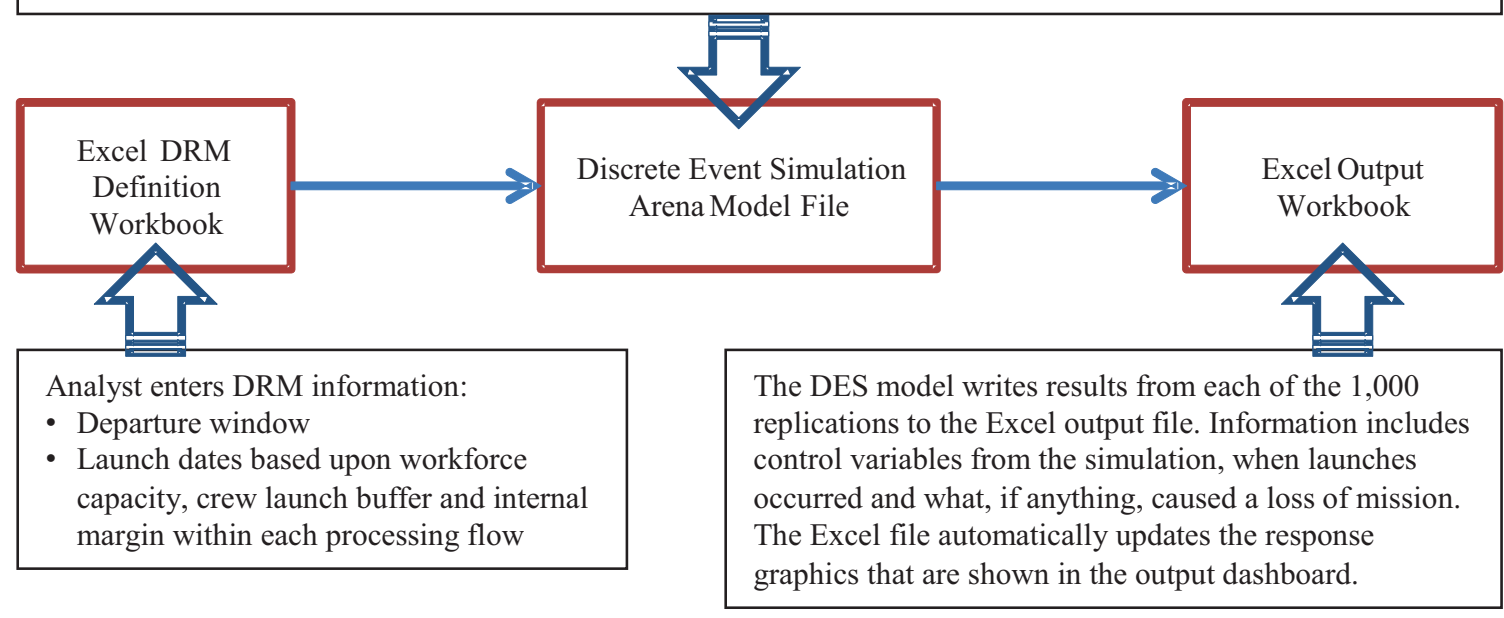

Figure 3 - Model Overview

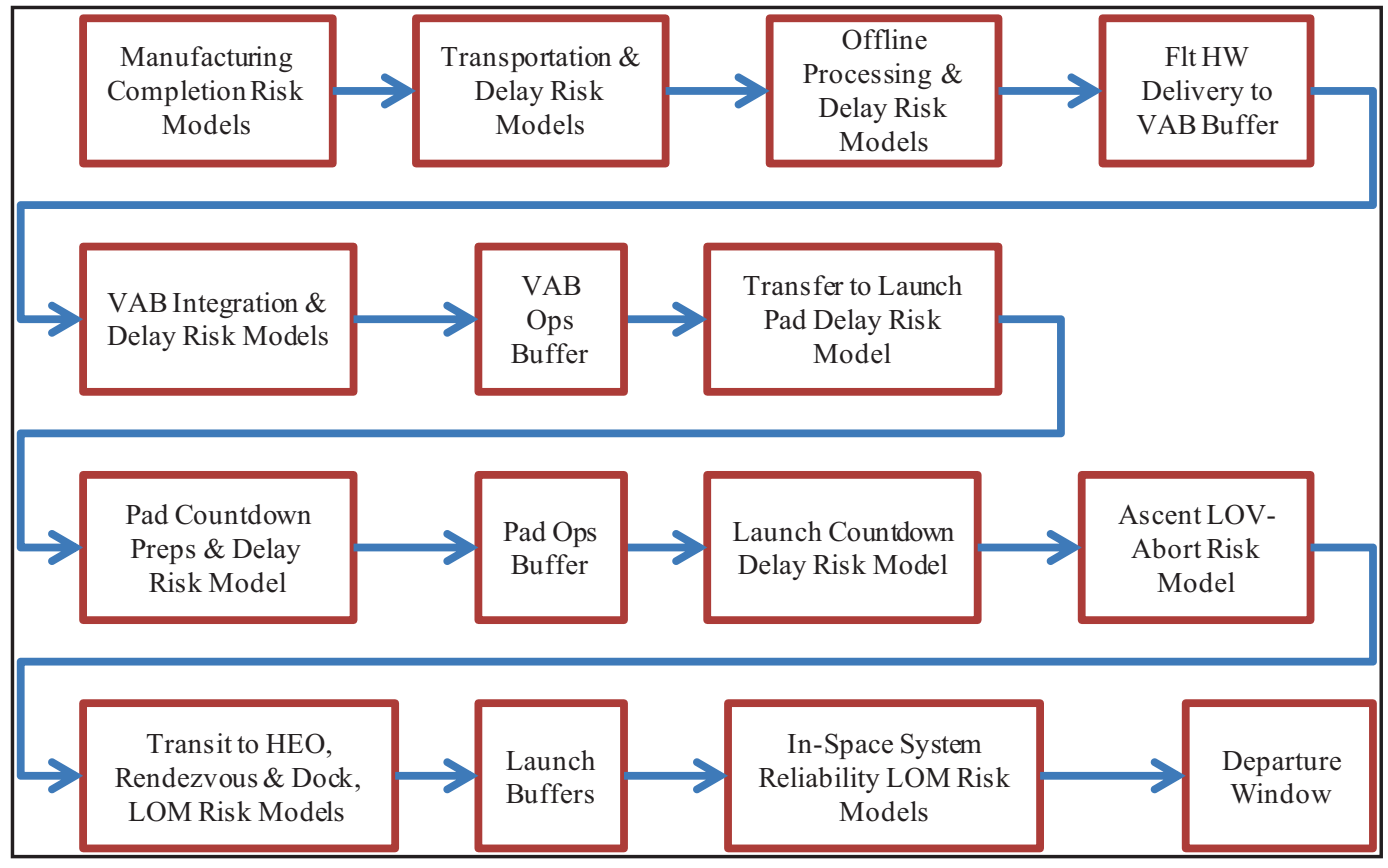

Figure 4 - Flight Hardware Elements Entity Routing Within Model 


\section{Overview of Risk Models}

Manufacturing \& Launch Campaign Risks-Delay risks through the start of launch countdown have been previously described in detail [9] and were used again for this analysis. The other risk elements of the model are described below.

Launch Countdown Delay Risk-The launch countdown delay risk models used for this analysis are based primarily upon Space Shuttle (a.k.a. STS) historical data coupled with the expected differences between the Space Shuttle and SLS. Figure 5 shows the actual cumulative launch distribution function created from the launch countdown history of 135 Space Shuttle missions along with the projected launch countdown delay distribution functions for the $105 \mathrm{t}$ SLS (both crew and cargo variants) and the $130 \mathrm{t}$ cargo SLS.

The projected distributions lie below the STS distribution for a number of reasons, including: 4 versus 3 Space Shuttle Main Engine (SSME) class engines; the ground architecture's limited capacity, relative to the capacity during the STS program, to perform consecutive propellant loadings of the SLS; the ground architecture's clean pad concept which limits the ability to perform troubleshooting at the launch pad and increases the likelihood of needing to roll-back to the VAB in the event of a technical scrub; and in the case of crewed launches, the need to consider the sea state conditions in the Orion ocean abort zones.

These projections are subject to a fair amount of uncertainty today, and to change in the future, given that the SLS, Orion, and payloads to be flown have not yet been developed, let alone established a launch history. For the time being they are believed to represent a reasonable estimate.

Ascent Loss of Mission Risk-For previous analysis, a range of values from $4.17 \mathrm{E}-3$ to $3.0 \mathrm{E}-2$ was used for the potential reliability of the SLS vehicle during ascent [9]. However, for this analysis, illustrative point estimates are used. Using historical information from the Space Shuttle experience (1 Solid Rocket Booster (SRB) failure and 1 SSME shutdown in 135 missions), a value of $1.716 \mathrm{E}-2$ was derived as shown in Table 2 for the ascent reliability of the $105 \mathrm{t}$ SLS. This estimate assumes that the vehicle uses twin SRBs similar to the STS and has 4 SSME class engines on the core stage as opposed to the 3 SSMEs used by the Space Shuttle.

For the 130 t SLS, twin liquid boosters with RD-180 class engines, $4 \mathrm{SSME}$ class engines on the core stage, and a liquid hydrogen/liquid oxygen $\left(\mathrm{LH}_{2}-\mathrm{LO}_{2}\right)$ upper stage with 1 or $2 \mathrm{~J} 2-\mathrm{X}$ engines are assumed. For the 4 SSME class engines on the cores stage, the estimate of 9.84E-3 is used as shown in Table 2 for $\mathrm{P}_{\mathrm{LOM}}$ for that portion of the vehicle.

The Apollo and Skylab J-2 experience and Centaur upper stage reliability provide useful analogs for estimating upper stage reliability on the $130 \mathrm{t}$ SLS. The Apollo and Skylab flight history for the J-2 consisted of 88 engines being flown with 1 engine shutdown event. This suggests a per engine failure rate of approximately 1.14E-2. The Centaur upper stage has a similar failure rate of approximately 1.2E-2 [13]. The analysis presented in this paper uses the $1.2 \mathrm{E}-2$ value for the future SLS upper stage.

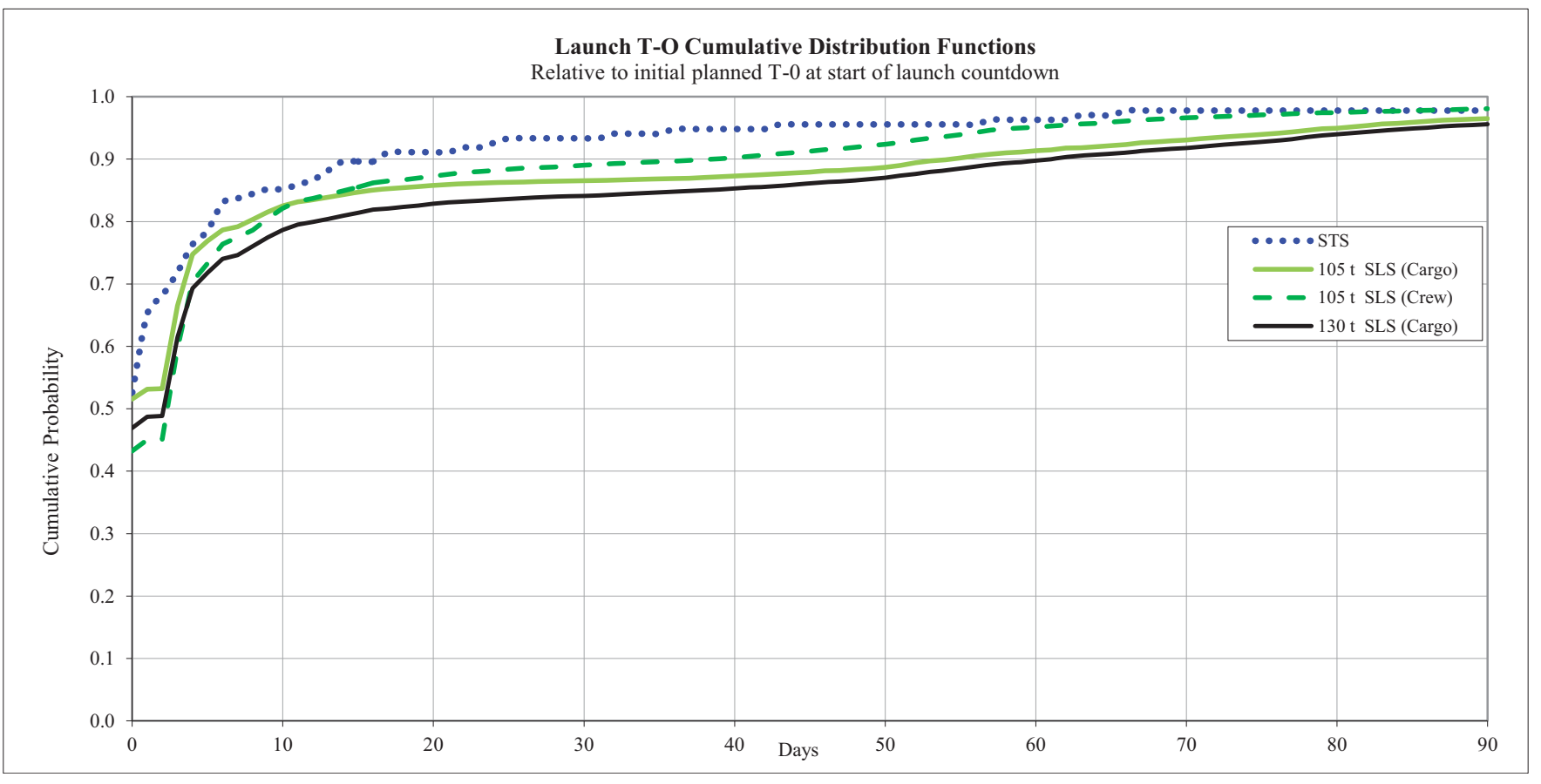

Figure 5 - Launch Countdown Delay Risk Models 
The Atlas $\mathrm{V}$ vehicle provides a potential analog for the reliability of the twin liquid booster. A study by the Futron Corporation places the expected Atlas V (401 variant) failure rate due to propulsion and separation events at $1.78 \mathrm{E}-2$ [14]. However, this value includes Centaur Upper Stage risk. Subtracting out the 1.2E-2 Centaur contribution yields a value of 5.87E-3 for the failure rate of the core stage of the Atlas V. This becomes the analog estimate for the SLS side stage failure rate. Since the SLS has twin side stages, the effective failure rate for the two side stages is $1.17 \mathrm{E}-2$.

Table 2. $105 \mathrm{t}$ SLS Loss of Mission (LOM) Risk Derivation

\begin{tabular}{|c|c|c|}
\hline & $\begin{array}{c}\text { Space Shuttle } \\
\text { SRBs (2) }\end{array}$ & $\begin{array}{c}\text { Space Shuttle } \\
\text { SSME (3) }\end{array}$ \\
\hline Flights & 135 & 135 \\
\hline Units per Flight & 2 & 3 \\
\hline Units flown & 270 & 405 \\
\hline Failures & 1 & 1 \\
\hline $\mathrm{P}_{\text {LOM }}$ per Unit & $3.70 \mathrm{E}-03$ & $2.47 \mathrm{E}-03$ \\
\hline Reliabilty & 0.9963 & 0.9975 \\
\hline \multicolumn{3}{|c|}{$\mathrm{P}_{\text {LOM }}$ with x Flight Units } \\
\hline 1 & 3.704E-03 & $2.469 \mathrm{E}-03$ \\
\hline 2 & 7.394E-03 & 4.932E-03 \\
\hline 3 & & $7.389 \mathrm{E}-03$ \\
\hline 4 & & $9.840 \mathrm{E}-03$ \\
\hline \multirow[t]{2}{*}{5} & & $1.228 \mathrm{E}-02$ \\
\hline & \multicolumn{2}{|c|}{105 t SLS } \\
\hline Ascent $P_{\text {LOM }}$ & \multicolumn{2}{|c|}{$1.716 \mathrm{E}-02$} \\
\hline Ascent Reliability & \multicolumn{2}{|c|}{0.9828} \\
\hline
\end{tabular}

Combining the side stage risk of $1.17 \mathrm{E}-2$ and the core stage engine risk of $9.84 \mathrm{E}-3$ produces a value of $2.143 \mathrm{E}-2$ for the $130 \mathrm{t}$ SLS first stage (twin side stages plus core stage). Adding the upper stage risk of $1.2 \mathrm{E}-2$ yields a combined ascent $\mathrm{P}_{\mathrm{LOM}}$ value of $3.317 \mathrm{E}-2$ for the $130 \mathrm{t}$ SLS.

If NASA were to develop a $130 \mathrm{t}$ SLS with liquid rocket booster (LRB) for lifting cargo, it is likely that the smaller $105 \mathrm{t}$ vehicle used to launch the crew would be modified to rely on liquid side boosters as well. Note that maintaining both an SRB and LRB capability in the future would likely prove to be too expensive. Consequently, when launch campaigns are analyzed in which the $130 \mathrm{t}$ vehicle is being used to launch cargo, it is assumed that the $105 \mathrm{t}$ utilizes the same LRBs. In that case the ascent reliability of the $105 \mathrm{t}$ SLS with LRB is $2.143 \mathrm{E}-2$.

Automated Rendezvous \& Docking Risk-The operations concept relies upon automated rendezvous and docking (ARD) for the various non-crewed elements making up the MTVs.
In previous studies, a range of values were used for the probability of ARD failure - from 1.5E-2 (optimistic) to 1.0E-1 (conservative). The Progress automated docking system has the most experience and is considered sufficiently reliable to be used on the ISS. However, a review of 45 automated Progress ISS docking missions found that in 7 of these missions the automated docking system failed to such an extent that the crew on board the ISS had to take over and conduct a manual rendezvous and docking [12]. This indicates a failure rate of approximately $1.6 \mathrm{E}-1$. There was also an instance where a resupply ship unintentionally impacted the Mir space station during a re-docking maneuver.

To narrow the scope of this analysis cycle, a point estimate documented in the report of the Exploration Systems Architecture Study (ESAS) was used. That study estimated the probability of failure for automated docking at 1 in 97 or $1.03 \mathrm{E}-2$ [15].

The probability of a rendezvous and dock failure for the crew-assisted Orion docking with the MTV is much lower than that for the automated procedure. The presence of the crew to take over in real time mitigates much of the risk. Additionally, the historical data for Space Shuttle and Soyuz crew docking with the Mir and ISS indicate a high level of reliability. The ESAS report estimated the docking failure rate at 1 in 230 or $4.35 \mathrm{E}-3$ [15].

System Reliability and MMOD Risks-Once established in orbit, an entity representing each major element of the MTVs is sent to a system reliability model and an MMOD risk model where there is a daily chance of a system failure or MMOD damage resulting in loss of mission. These daily risks of system failure or MMOD induced loss of mission for each MTV element in orbit continues until trans-Mars injection burn for that MTV.

Since these spacecraft have not been designed, built or operated yet, it is difficult to develop accurate risk models. In previous studies, it has been estimated that the per element MMOD risk for elements in LEO is between $5.1 \mathrm{E}-6$ and 5.1E-5 per day. The wide range in values reflects difference in element size and design, particularly in the amount of MMOD protection incorporated in the element, and differences in orbit and orientation. For this study a value of 1.0E-5 per MTV element per day was used. This represents a somewhat optimistic value, reflecting the assumption that significant MMOD protection would be incorporated into MTV elements.

Additional factors were considered while estimating the system reliability risk models for the various MTV elements launched into orbit. These included the complexity of the element, whether or not the ISS provided a reasonable analog, and the absence during most of the MTV assembly period of a crew to identify problems and effect repairs to preclude loss of mission. The chosen values shown in Table 3 are subjective. 
Table 3. System Failure Rates (Per Day in LEO) Used in This Study

\begin{tabular}{|l|c|}
\hline MTVElements & P $_{\text {LOM }}$ \\
\hline HAB & $1.00 \mathrm{E}-04$ \\
\hline SHAB & $1.00 \mathrm{E}-04$ \\
\hline MDAV & $1.00 \mathrm{E}-05$ \\
\hline Orion & $1.00 \mathrm{E}-05$ \\
\hline $\begin{array}{l}\text { Propulsion } \\
\text { Elements }\end{array}$ & $2.50 \mathrm{E}-06$ \\
\hline
\end{tabular}

Crew Medical Risk-Once the crew is launched into Earth orbit and up until the departure burn for Mars, there is the potential that a crew medical event will prompt a decision to return the ailing crew member to Earth. This scenario results in a loss of mission.

Inputs for the crew health risk model are based upon work performed by NASA's Integrated Medical Model (IMM) project team [16]. The IMM is being developed to respond to a significant need identified in NASA's Human Research Roadmap [17] to quantify likelihood and consequence of medical conditions that could occur in spaceflight [18].

Based upon inputs from the IMM community, daily rates of 7.19E-5, 9.72E-5 and 2.05E-4 LOM health events per astronaut-day respectively for the optimistic, neutral, and conservative risk settings were previously used [9]. To reduce the number of simulation runs for this study, the neutral value was assumed for all cases. The planned date for launching the crew relative to the opening of the departure window was also held constant.

Departure Burn Risk-The culmination of the launch and assembly campaign is the trans-Mars injection burn for each MTV. This is essentially another upper stage burn so the Centaur failure probability value, $1.2 \mathrm{E}-2$ that was previously discussed, was assumed. Note that, since there is very little data available regarding NTR reliability, the same value was assumed for both the Chemical and NTR options. There may actually be significant reliability differences between these two propulsion types.

\section{Summary of Risk Factors}

A summary of the post-launch risk factor settings is shown in Table 4.
Table 4. In-Flight Risk Settings

\begin{tabular}{|c|c|c|}
\hline \multicolumn{2}{|r|}{ Risk Factors } & $P_{\text {LOM }}$ \\
\hline \multirow{4}{*}{ Ascent } & $105 \mathrm{t}$ SLS & $1.716 \mathrm{E}-02$ \\
\hline & 105 t SLS with LRBs & 2.142E-02 \\
\hline & 130 t First Stage & 2.142E-02 \\
\hline & $130 \mathrm{t}$ Upper Stage & $1.200 \mathrm{E}-02$ \\
\hline \multirow{2}{*}{$\begin{array}{l}\text { Rendezvous, } \\
\text { Proximity } \\
\text { Operations \& } \\
\text { Docking/ } \\
\text { Connection }\end{array}$} & $\begin{array}{l}\text { Automated } \\
\text { (Between MTV } \\
\text { Elements) }\end{array}$ & $1.030 \mathrm{E}-02$ \\
\hline & $\begin{array}{l}\text { Crew Directed } \\
\text { (Orion to MTV) }\end{array}$ & 4.350E-03 \\
\hline \multirow{5}{*}{$\begin{array}{l}\text { System } \\
\text { Reliability } \\
\text { Per Element } \\
\text { Per Day } \\
\text { On Orbit }\end{array}$} & HAB & 1.000E-04 \\
\hline & SHAB & 1.000E-04 \\
\hline & MDAV & $1.000 \mathrm{E}-05$ \\
\hline & Orion & $1.000 \mathrm{E}-05$ \\
\hline & \begin{tabular}{|l|} 
Propulsion \\
Elements
\end{tabular} & $2.500 \mathrm{E}-06$ \\
\hline MMOD & All Elements & $1.000 \mathrm{E}-05$ \\
\hline Health & $\begin{array}{l}\text { Per Person } \\
\text { Per Day on Orbit }\end{array}$ & $9.720 \mathrm{E}-05$ \\
\hline $\begin{array}{l}\text { Departure } \\
\text { Burn }\end{array}$ & For each MTV & $1.200 \mathrm{E}-02$ \\
\hline
\end{tabular}

\section{Running the Model}

The simulation ends when either there has been a loss of mission event or the trans-Mars injection has occurred. 1,000 replications of the simulation are executed to obtain a large data set to analyze. At the end of each replication, the model writes results in an Excel output file. In addition to writing the results to the output file, the deterministic inputs and assumptions that were used during the experiment are also written to the output file. An example of the dashboard that the analyst sees is shown in Figure 6. The upper two-thirds of the dashboard presents the launch and assembly sequence that the simulation attempts to execute in each of the 1,000 replications. The experimental results are shown in the bottom third.

The ground processing assumptions are identified in the far left column cells. The next two columns identify the MTV payload element being launched along with its respective system failure risk and MMOD risk while loitering in LEO during the assembly campaign. The Gantt chart in the middle of the figure shows the various launch vehicle stacking, payload integration, and pad flow operations. Note that there is a color code above the Gantt chart (white for transportation and offline processing, blue for launch vehicle stacking, red for payload integration and so on). Also the flow of the launches is from bottom to top and from left to right such that the Earth departure window for Mars, shown in magenta, is shown in the upper right corner of the Gantt chart. 


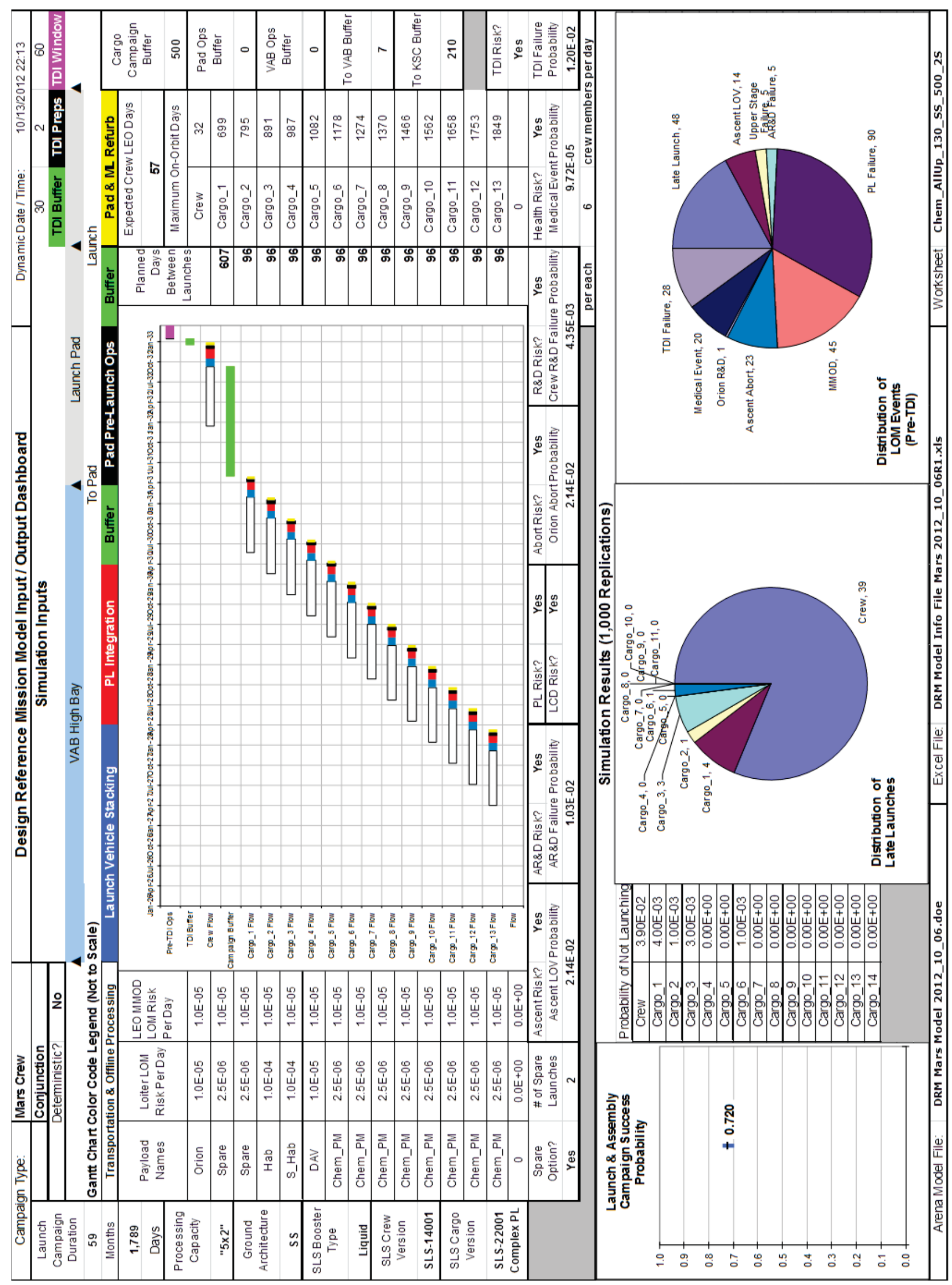

Figure 6 - Model Output Dash Board Example 
Green bars indicate available schedule margin (buffers). In this example there is a 500 day buffer between the last cargo launch and start of launch vehicle stacking for the Orion launch. There is a 30-day buffer between the Orion planned launch date and the opening of the departure window.

To the right of the Gantt chart are cells that identify the various launch flows by name along with planned time between launch dates and maximum days on orbit for each of the MTV payload elements.

The major risk model probabilities used in the simulation are identified along the bottom rows of the dashboard. Additionally, in the bottom left corner are a couple of cells that identify whether or not this analysis included the option for spare launches, and if so how many spares were available.

The bottom third of the dashboard displays the simulation results that correspond to the scenario described above. The chart on the left indicates the probability for how many of the 1,000 replications successfully completed the trans-Mars injection burn. This is the metric to be maximized.

The pie chart on the far right side identifies the number and proportion of failures for each of the major LOM categories: launch campaign failing to launch all launches; ascent failures; upper stage failures; AR\&D failures; payload system failures; MMOD; failure of the SLS launching Orion resulting in an Orion ascent abort mode; Orion Rendezvous and dock failures, medical LOM events; and transdestination injection (TDI) burn failures.

The pie chart in the middle identifies the launches that were late and caused a late-launch LOM. The table to the left of this pie chart provides the probability of not launching for each of the launches in the campaign.

The bottom row of the dashboard identifies the Arena model file name, the Excel file that is associated with that model, and the worksheet where the experiment results reside.

\section{Description of CASES ANALyZED}

Eight unique cases were explored representing the $2 \mathrm{MTV}$ propulsion types, the $2 \mathrm{MTV}$ deployment strategies and the 2 SLS cargo variants, as shown in Table 5. For each of these cases, the trade space also included Ground Architecture capacity drivers (single string vs. dual string facilities and $5 \times 2$ vs. $5 \times 3$ processing) and number of spares ( 0,1 or 2$)$. In addition, cargo campaign buffer durations were varied to determine an optimum buffer size. Optimum buffer sizes were used in the analysis for each case and shown in the results.

Each case in the trade space was analyzed with the model containing the risk factor settings previously described.

Table 5. Trade Space

\begin{tabular}{|c|c|c|c|c|c|c|c|}
\hline $\begin{array}{c}\text { Case } \\
\#\end{array}$ & $\begin{array}{l}\text { MTV } \\
\text { Prop. } \\
\text { Type }\end{array}$ & $\begin{array}{c}\text { MTV } \\
\text { Deploy }\end{array}$ & $\begin{array}{c}\text { Number } \\
\text { of }\end{array}$ & $\begin{array}{c}\text { Cargo } \\
\text { SLS } \\
\text { Version }\end{array}$ & \multicolumn{2}{|c|}{$\begin{array}{c}\text { Ground } \\
\text { Architecture }\end{array}$} & Spares \\
\hline 1 & \multirow{2}{*}{ Chem } & \multirow{2}{*}{ All Up } & 13 & $105 \mathrm{t}$ & \multirow{8}{*}{$\begin{array}{l}\text { Single } \\
\text { String }\end{array}$} & \multirow{5}{*}{$5 \times 2$} & \multirow{8}{*}{$0,1,2$} \\
\hline 2 & & & 12 & $130 \mathrm{t}$ & & & \\
\hline 3 & \multirow{2}{*}{ NTR } & \multirow{2}{*}{ All Up } & 11 & $105 \mathrm{t}$ & & & \\
\hline 4 & & & 10 & $130 \mathrm{t}$ & & & \\
\hline 5 & \multirow{2}{*}{ Chem } & \multirow{2}{*}{$\begin{array}{c}\text { Pre- } \\
\text { Deploy }\end{array}$} & 8 and 5 & $105 \mathrm{t}$ & & & \\
\hline 6 & & & 6 and 5 & $130 \mathrm{t}$ & & \multirow[t]{3}{*}{$5 \times 3$} & \\
\hline 7 & \multirow{2}{*}{ NTR } & \multirow{2}{*}{$\begin{array}{c}\text { Pre- } \\
\text { Deploy }\end{array}$} & 6 and 4 & $105 \mathrm{t}$ & & & \\
\hline 8 & & & 5 and 4 & $130 \mathrm{t}$ & & & \\
\hline
\end{tabular}

\section{RESULTS}

The summary level results are shown in Figures $7 \& 8$. Figure 7 displays the results for the 8 cases with single string, $5 \times 2$ processing assumptions. Figure 8 displays the results for the 8 cases with dual string, $5 \times 3$ processing assumptions. For both figures, the number of spares is varied from 0,1 and 2 . The 0 spares case is the bottom point in the column, the 1 spare is the middle point in the column and the 2 spares is the top point in the column.

The pre-deploy cases consist of two launch and assembly campaigns. The first campaign launches and assembles MTV-1 and MTV-2, which are sent on their way to Mars 26 months prior to the crew being sent. The second campaign launches and assembles MTV-3, which has the crew being launched last and as close as practical to the opening of the departure window so as to minimize crew time on orbit. This operational concept has significant implications for the launch and assembly campaigns.

Detailed results for each of the 8 cases are shown in the Appendix. 
Single String, 5X2 Processing

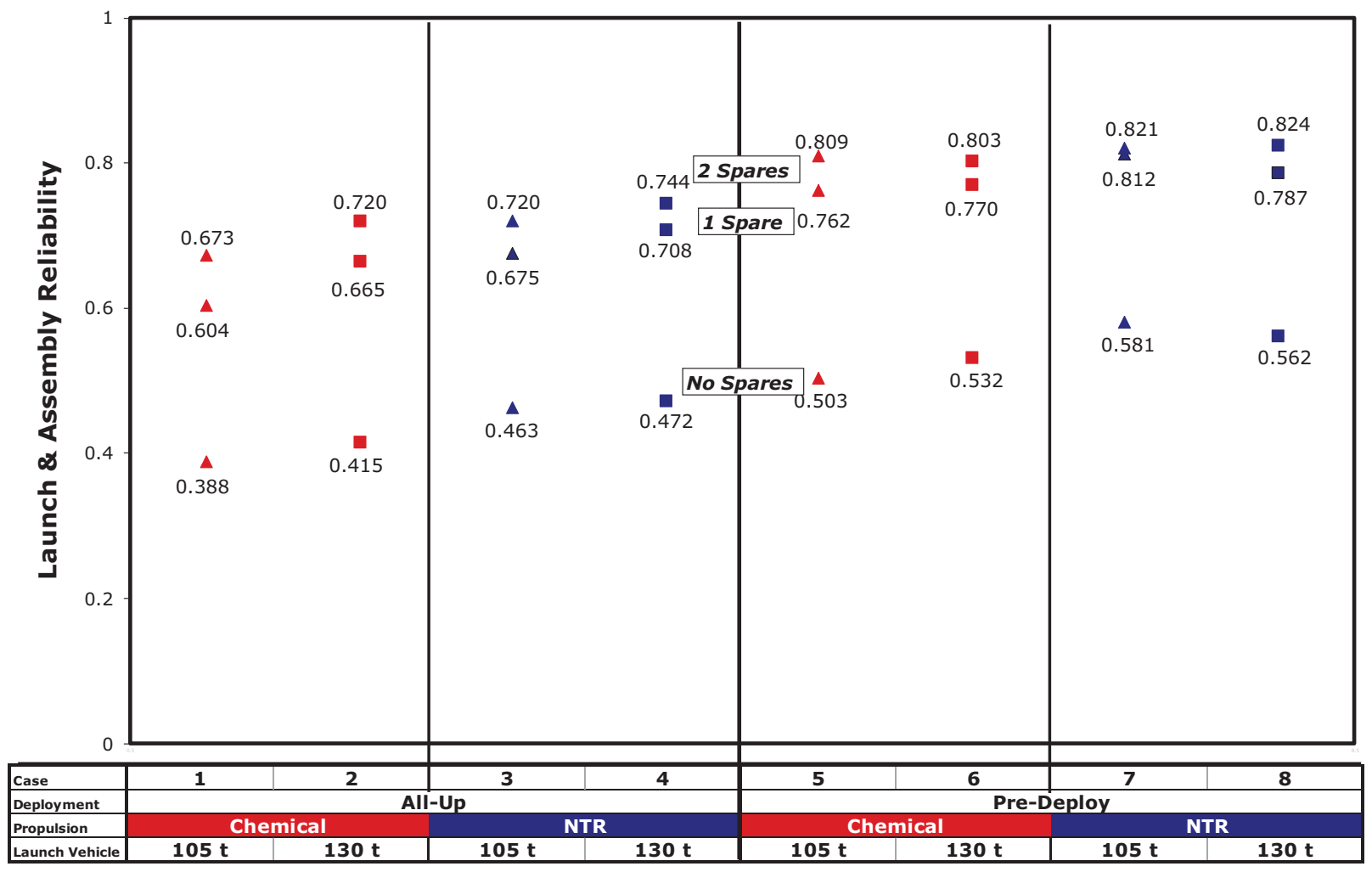

Figure 7 - Launch and Assembly Reliability for Single String, 5x2 Processing

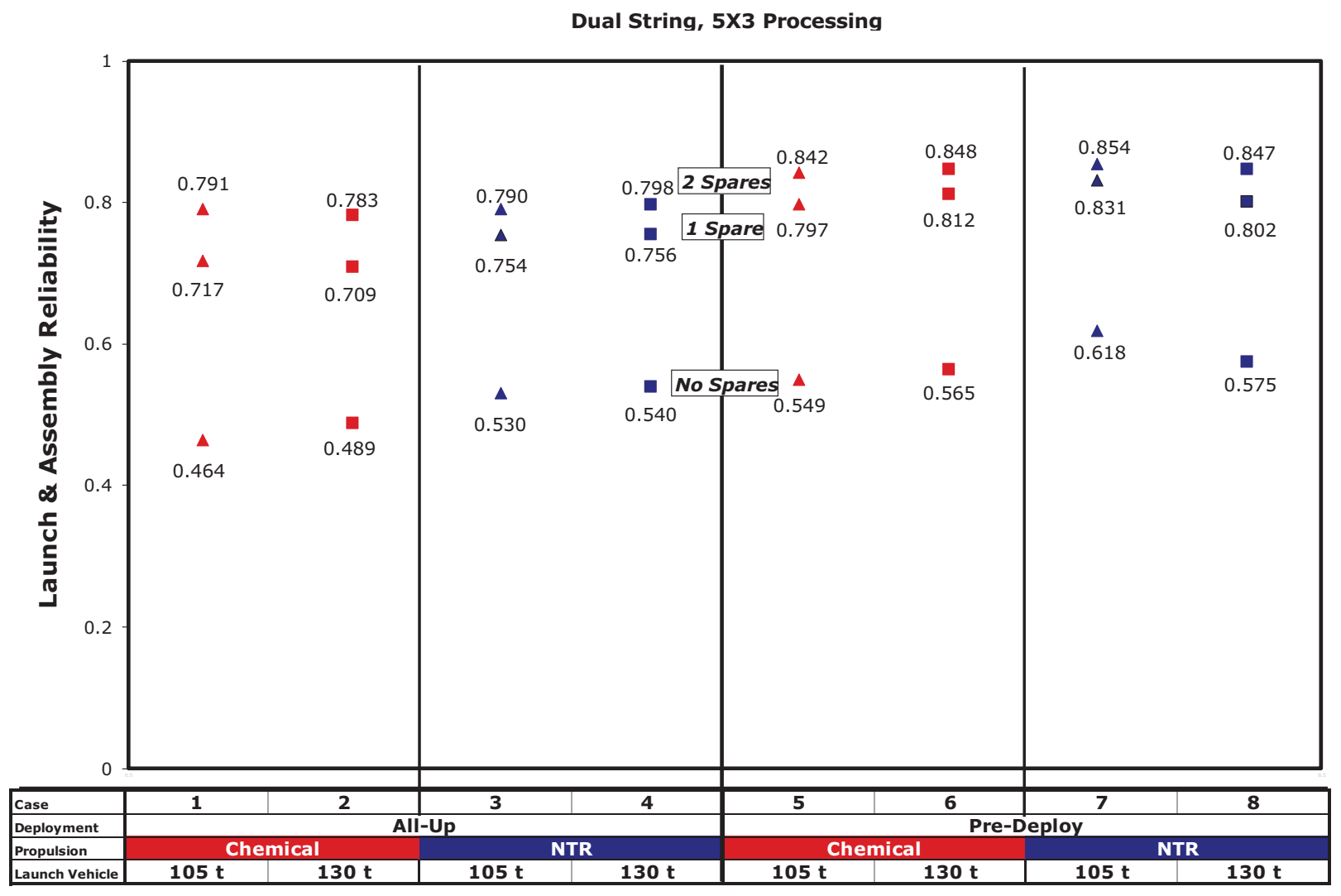

Figure 8 - Launch and Assembly Reliability for Dual String, 5x3 Processing 
The results of this analysis indicate several trends in launch and assembly reliability:

- The cases in which cargo is pre-deployed to Mars at an opportunity prior to crew departure provide significantly improved reliability over the all-up cases. Allowing the two cargo MTVs to be launched and assembled for a prior opportunity effectively isolates those activities from those required to send the crew. This limits the total number of launches and elements to be assembled prior to each departure window, lessening the overall probability of failure. It is important to keep in mind that the improved launch and assembly reliability for the pre-deployed cases may be offset by the added duration that the pre-deployed assets have to wait at Mars for the crew to arrive. This potential offset should be assessed in the future as part of a total mission risk assessment process.

- In most cases the $130 \mathrm{t}$ launch vehicle provides for a higher launch and assembly reliability than the $105 \mathrm{t}$. This is due to the lower number of launches required to place the elements in LEO for the larger launch vehicle. However, these benefits are largely offset by the decrease in launch reliability for the larger capacity launch vehicle, associated with the liquid boosters and upper stage.

- Having a dual-string ground processing and launch architecture also provides benefit over a single string capability. The dual-string capability lowers the required time between launches and helps limit propagating delays. The benefits of the dual-string capability are more pronounced in the all-up cases and for the chemical propulsion cases, where there is greatest total number of launches per opportunity.

- Nuclear Thermal Propulsion for the MTVs results in greater launch and assembly reliability across the board, as compared to the equivalent chemical propulsion cases. This is due to the lower number of total required launches for each MTV. It should be noted though that this analysis does not consider any additional risks that might be incurred through the use of NTR.

- The most significant improvements in launch and assembly reliability were associated with the availability of spare launch vehicles and elements to be used in the event of a launch or assembly failure. The addition of spare hardware to a campaign generally increased overall reliability from values that averaged approximately 0.5 across all cases to average values of 0.75 and 0.80 , for the one and two spares cases, respectively. The sparing strategy that was modeled assumed that the spare launch vehicle and payload element could be used to replace any failed payload element. While the launch vehicles are essentially interchangeable, the same cannot be said about the payload elements. Consequently, in order to realize all of the reliability improvement, each payload element would need to have a ready spare.

\section{Sensitivity Analysis}

A major goal in the development of the launch and assembly reliability analysis was to enable sensitivity analysis for critical parameters. Sensitivity analysis allows the agency to identify and improve parameters that will most directly contribute to improved reliability. The simulation model allows for sensitivity analysis of any parameter. Cases involving varying crew parameters where selected to illustrate this capability.

The launch campaigns ending with a crewed Orion launch have low reliability relative to the cargo only campaigns. The primary reasons lowering the reliability are related to crew health risks and launching the crew in close proximity to the departure window without backup should the launch fail to deliver the crew to their MTV. Sensitivity analysis is used to understand how to increase the launch and assembly campaign reliability.

For the sensitivity analysis, Case 8 (Nuclear MTV Propulsion, Pre-Deployment of MTVs 1\&2, and the $130 \mathrm{t}$ SLS) - Scenario 6 (dual string ground architecture with $5 \times 3$ processing and 2 spares) was selected. This Case-Scenario combination had a success probability of approximately 0.847 as shown in Figure 8. The results were analyzed for sensitivity to: (1) launching the crew earlier; (2) an alternate value for the crew health risk factor; (3) reducing the crew size; and (4) having a backup crew and launch vehicle.

The results for the 4 additional scenarios are displayed in Figure 9. The results for each scenario are presented using a consistent format showing the launch campaign success probability $95 \%$ confidence interval, along with the midpoint of that interval. The table at the bottom of the figure highlights in yellow key model parameters that were changed relative to the initial settings for Scenario 6 .

In Scenario 7, the constraint that the planned launch of the crew be held at a constant date relative to the opening of the Earth orbit departure window was relaxed. In all the scenarios analyzed previously the planned crew launch date provided 30 days of schedule margin for launch delays. As it turned out, a value of 30-days was very close to optimum. A very modest improvement was found by adding an additional 5 days of margin (from 30 days to 35 days).

In Scenario 8, the crew health risk value was changed to 7.2E-05 for the risk of loss of mission per crew member per day on orbit. This value represented the most optimistic value received from the medical community described earlier. The simulation results show a very modest improvement. 


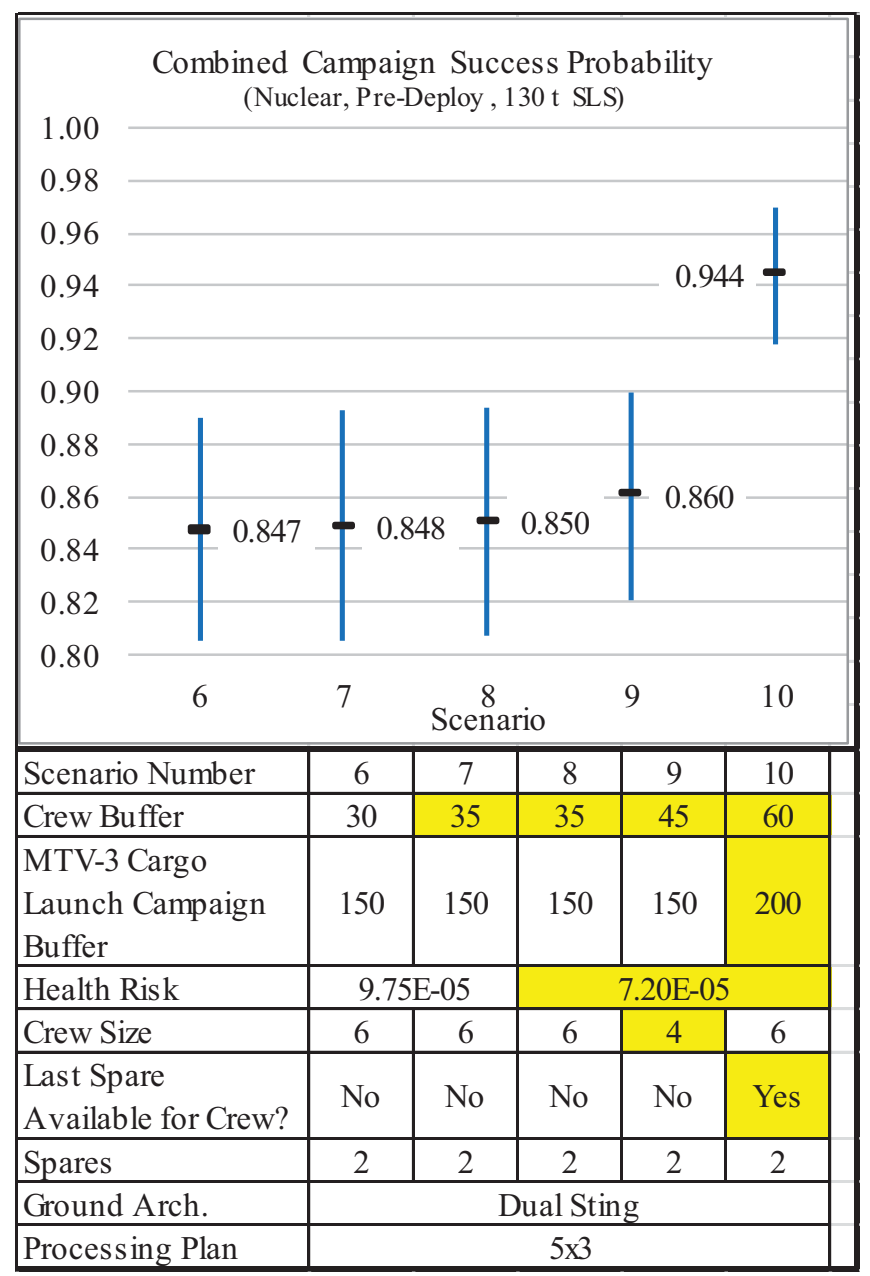

Figure 9 - Sensitivity Analysis for Case 8 (Pre-Deploy, NTR, 130 t SLS)

In Scenario 9, the crew size was reduced from 6 to 4 to see how much improvement in reliability could be achieved by reducing risk of a loss of mission due to a medical event. Reducing the crew size, coupled with the improved crew health risk value, provided a modest improvement. Note that the optimum crew buffer size was found to be 45 days. However, the projected campaign success probability probably needs to be higher. Note that reducing the crew size would also reduce launch mass and potentially the number of launches required. These potential benefits were not analyzed, but should be considered in the future when trading crew size.

Finally, in Scenario 10, the launch campaign was rearranged so that the second of the two available spare launches is held on the ground until after the crew launches. In this way, the final spare vehicle is available to be launched in support of a failed crew mission or any of the other payload elements that have been previously placed on orbit should they have failed. The concept would require that the launch vehicle be ready for integration when a launch or on-orbit failure occurs and requires rapid integration with either a payload element or a crew vehicle. Alternatively, one could have a third spare launch vehicle pre-configured for a crewed launch.
The optimum value for the crew launch buffer was determined to be 60 days. Additionally, the optimum buffer for the cargo launches prior to the crew launch was found to be 200 days. Scenario 10 provides a significant benefit and places the projected campaign success probability at approximately 0.94 .

Having a backup launch to support a crewed launch is not without precedent. For the last space shuttle servicing mission to the Hubble Space Telescope, a second space shuttle was on an alternate launch pad ready to launch in case the launched mission suffered damage to its thermal protection system such that the crew needed to be rescued [19].

\section{CONCLUSIONS AND FORWARD WORK}

A capability to perform integrated launch and assembly campaign reliability risk for human exploration of Mars has been established.

Initial findings indicate a significant relationship between the risk factor settings and mission success. Consequently, it will be important going forward to obtain an accurate estimate for the Space Launch System's ascent reliability, the reliability of the planned rendezvous and docking systems, the reliability and MMOD resilience of the mission elements once they have been placed in orbit by the SLS, and the crew health risks. Understanding the investment required to achieve reliability improvements and crew health risk mitigation will also be key to making informed trades.

A significant finding is that having spare launches (along with spare payload elements) seems to be key to the viability of any launch and assembly campaign regardless of the concept of operations parameters - MTV propulsion type, MTV deployment strategy, SLS capacity, or ground architecture assumptions.

Forward work includes updates to risk factors and adding additional constraints as they emerge from the NASA programs designing, building and operating the systems that will be required for human exploration of Mars. 


\section{REFERENCES}

[1] Drake, B.G., "Human Exploration of Mars, Design Reference Architecture 5.0" NASA-SP-2009-566, July 2009.

[2] Drake, B.G., "Human Exploration of Mars, Design Reference Architecture 5.0 Addendum" NASA-SP-2009566-ADD, July 2009.

[3] Cates, G.R., Steele, M.J., Mollaghasemi, M., and Rabadi, G., "Modeling the space shuttle," In Proceedings of the 2002 Winter Simulation Conference, ed. E. Yücesan, C.H. Chen, J. L. Snowdon, and J. M. Charnes, 754-762.

[4] Cates, G.R. and Mollaghasemi, M., "Supporting The Vision For Space With Discrete Event Simulation," In Proceedings of the 2005 Winter Simulation Conference, M. E. Kuhl, N. M. Steiger, F. B. Armstrong, and J. A. Joines, eds., 1306-1310.

[5] Cates, G.R., and Mollaghasemi, M., "A Discrete Event Simulation Model For Assembling The International Space Station," In Proceedings of the 2005 Winter Simulation Conference, M. E. Kuhl, N. M. Steiger, F. B. Armstrong, and J. A. Joines, eds., 1260-1264.

[6] Stromgren, C. et al, "Launch Order, Launch Separation and Loiter in the Constellation $1 \frac{1}{2}$ Launch Solution," 2009 IEEE Aerospace Conference, 978-1-4244-2621-8, 2009 .

[7] Cates, G.R., et al, "Low earth orbit rendezvous strategy for lunar missions," Proceedings of the IEEE 2006 Winter Simulation Conference, 1-4244-0500-9, 2006.

[8] Cirillo, W.M, et al, "Risk Analysis of On-Orbit Spacecraft Refueling Concepts," AIAA Space 2010 Conference \& Exposition, AIAA-2010-8832, 30 Aug. - 2 Sep. 2010, Anaheim, California.

[9] Cates, G.R., et al, "Launch and Assembly Reliability Analysis for Human Space Exploration Missions," 2012 IEEE Aerospace Conference, 2012

[10] Thunnissen, D.P., "Balancing Cost, Risk, and Performance Under Uncertainty in Preliminary Mission Design,” AIAA Paper 2004-5878, September 2004.

[11] Rockwell Automation's Arena: http://www.arenasimulation.com/

[12] Ascend, "Space Review: World Launch History," "Soyuz Launch Vehicle," and Ascend's SpaceTrak database: www.ascendspacetrak.com (subscription required)
[13] Smith, K.R. et al, "Cryogenic Upper Stage System Safety," Proceedings of the $1^{\text {st }}$ IAASS Conference, 25-27 Oct. 2005, Nice, France. Also available on NASA Technical Reports Server Document ID 20050242041 http://ntrs.nasa.gov/archive/nasa/casi.ntrs.nasa.gov/20050 242041 2005246348.pdf

[14] Futron Corporation, "Design Reliability Comparison for SpaceX Falcon Vehicles," November 2004: http://www.spacex.com/FutronDesignReliability.pdf

[15] NASA, "Exploration Systems Architecture Study," page $598,2005$.

[16] Butler, D.J. and Kerstman E., "The Integrated Medical Model," presentation to NASA Human Research Program Investigators' Workshop, 4 Feb. 2010:

http://ntrs.nasa.gov/archive/nasa/casi.ntrs.nasa.gov/20100 $\underline{005626 \text { 2010005183.pdf }}$

[17] NASA Human Research Roadmap website: http://humanresearchroadmap.nasa.gov/

[18] NASA Human Research Roadmap Gap ExMC 2.01: http://humanresearchroadmap.nasa.gov/Gaps/?i=384

[19] Hamlin, T.L., Canga, M.A., and Cates, G.R., "Hubble Space Telescope Crew Rescue Analysis," In Proceedings of the 10th International Probabilistic Safety Assessment \& Management Conference, 7-11 June 2010, Seattle Washington. 


\section{BIOGRAPHIES}

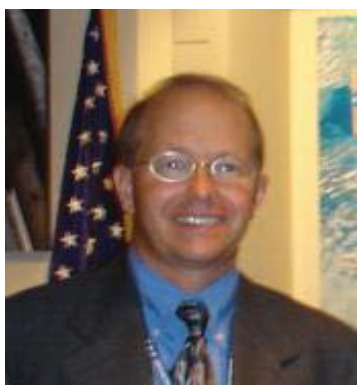

Grant Cates is a Senior Operations Research Analyst at SAIC. He retired from NASA in 2006 after 25 combined years in federal service, including 7 years on active duty in the Air Force. At NASA he served in varying capacities on the Space Shuttle Program, including Space Shuttle Columbia Vehicle Manager and Flow Director. He received a Ph.D. in Industrial Engineering from the University of Central Florida in 2004.

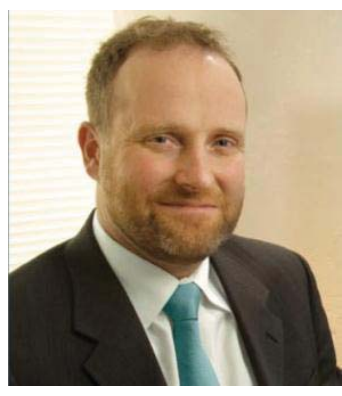

Chel Stromgren currently serves as the Chief Scientist of Binera, Inc. Risk Analytics Division. In this role, Mr. Stromgren leads the development of probability and risk-based strategic models and strategic analysis of complex system development. Mr. Stromgren has supported NASA in the analysis of Space Shuttle and International Space Station operations in the post-Columbia environment and has led the development of strategic campaign models for the lunar exploration initiatives. He holds a Bachelor of Science degree in Marine Engineering and Naval Architecture from the Webb Institute and a Master of Science degree in Systems Management from the Massachusetts Institute of Technology.

\section{APPENDIX}

The detailed results for each case are presented using a consistent format showing the launch campaign success probability $95 \%$ confidence interval, along with the midpoint of that interval. For each case, results are shown for the 6 different scenarios that we explored. Scenarios 1-3 are with the single-string ground architecture and $5 \times 2$ processing. Scenarios 4-6 have the dual-string ground architecture with $5 \times 3$ processing. Scenarios 1 and 4 represent the maximum success probability that could be achieved without adding spares into the launch campaign. Scenarios 2 and 5 are based upon campaigns having 1 spare and Scenarios 3 and 6 are based upon launch campaigns having 2 spares.

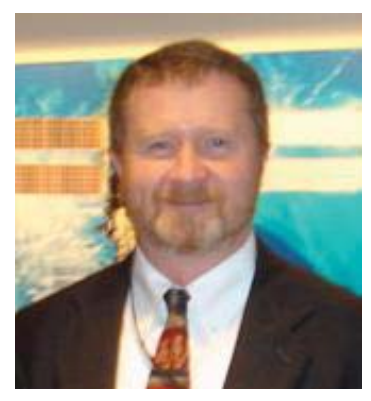

William Cirillo currently serves as a Senior Researcher at NASA Langley Research Center in Hampton, Virginia, where he has worked for past 20 years in the area of Human Space Flight Systems Analysis. This has included studies of Space Shuttle, International Space Station, and Human Exploration beyond low Earth orbit. In 2005, Mr. Cirillo served at NASA Headquarters as a core member of the Exploration Systems Architecture Study (ESAS) team, where he was responsible for studying the use of Ares I/Orion in meeting future ISS crew and logistics transportation needs. Mr. Cirillo currently leads a team of analysts in assessing at a strategic and tactical level the manifesting of assembly and logistics flights human exploration beyond low Earth orbit.

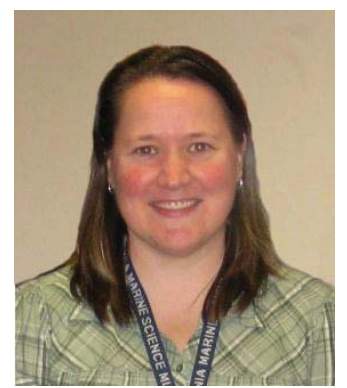

Kandyce Goodliff is an aerospace engineer at NASA Langley Research Center in Hampton, VA, with the Space Mission Analysis Branch (SMAB). Her primary roles as a systems analyst for SMAB are conceptual design and sizing of human and robotic spacecraft, mission and spacecraft analysis, and campaign analysis for human exploration. She has a Bachelor of Science in Aerospace Engineering from Embry-Riddle Aeronautical University and a Master of Science in Mechanical Engineering from the George Washington University.

The All-Up cases (Cases 1-4) are presented first followed by the Pre-Deploy cases (Cases 5-8). In order to determine the success probabilities for the Pre-Deploy cases, the cases are split into the pre-deployment campaigns for MTV-1 \& 2 and the MTV-3 campaign (crew launch). The results for the MTV-1 \& 2 campaign were then combined with the MTV-3 campaigns to obtain the combined campaign reliability for Cases 5-8 that were shown in Figure 7 and Figure 8.

One thing to note is the wide range in duration of the launch and assembly campaign as shown in the tables below each of the results figures. 
Detailed Results for All-Up Cases

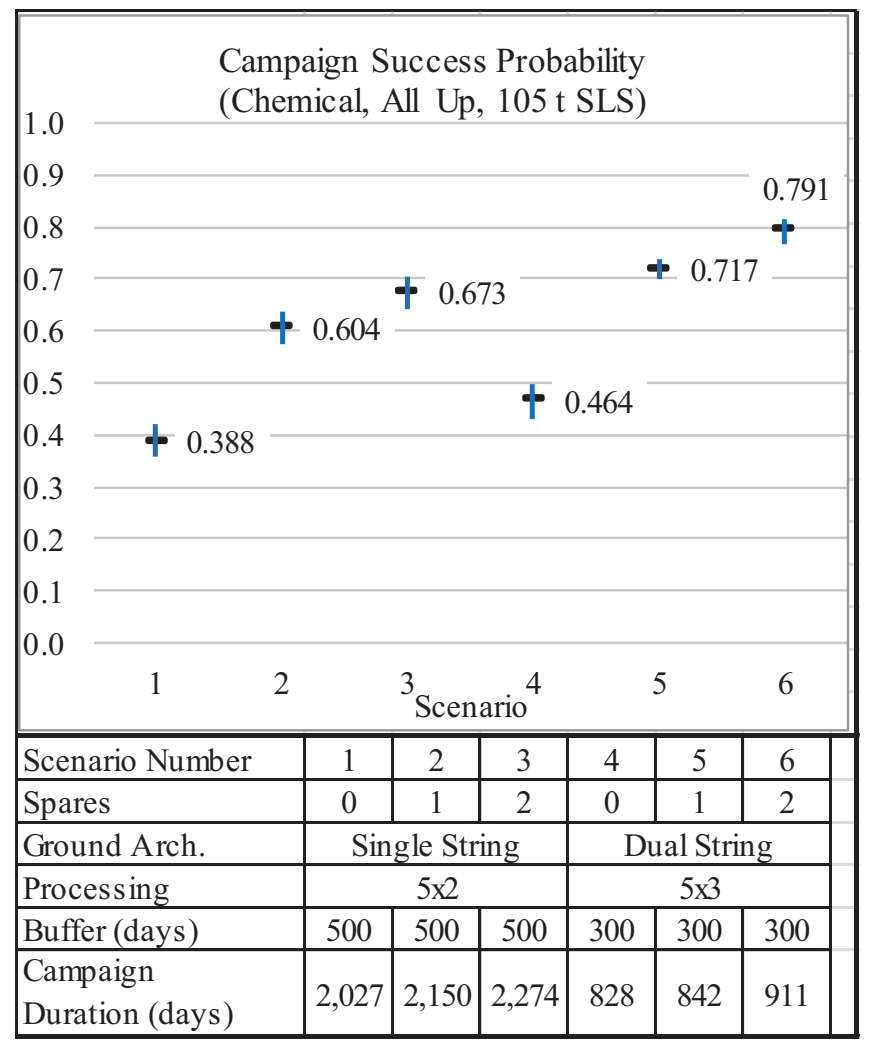

Figure 10 - Case 1 Summary Results

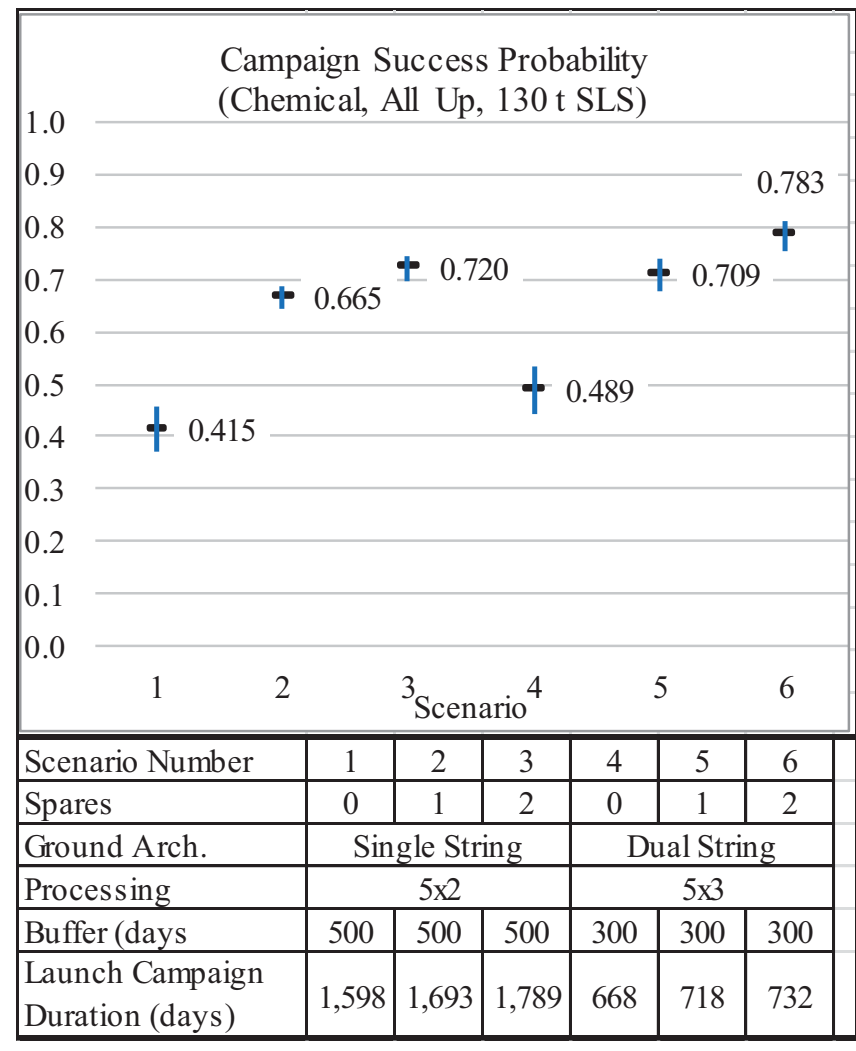

Figure 11 - Case 2 Summary Results

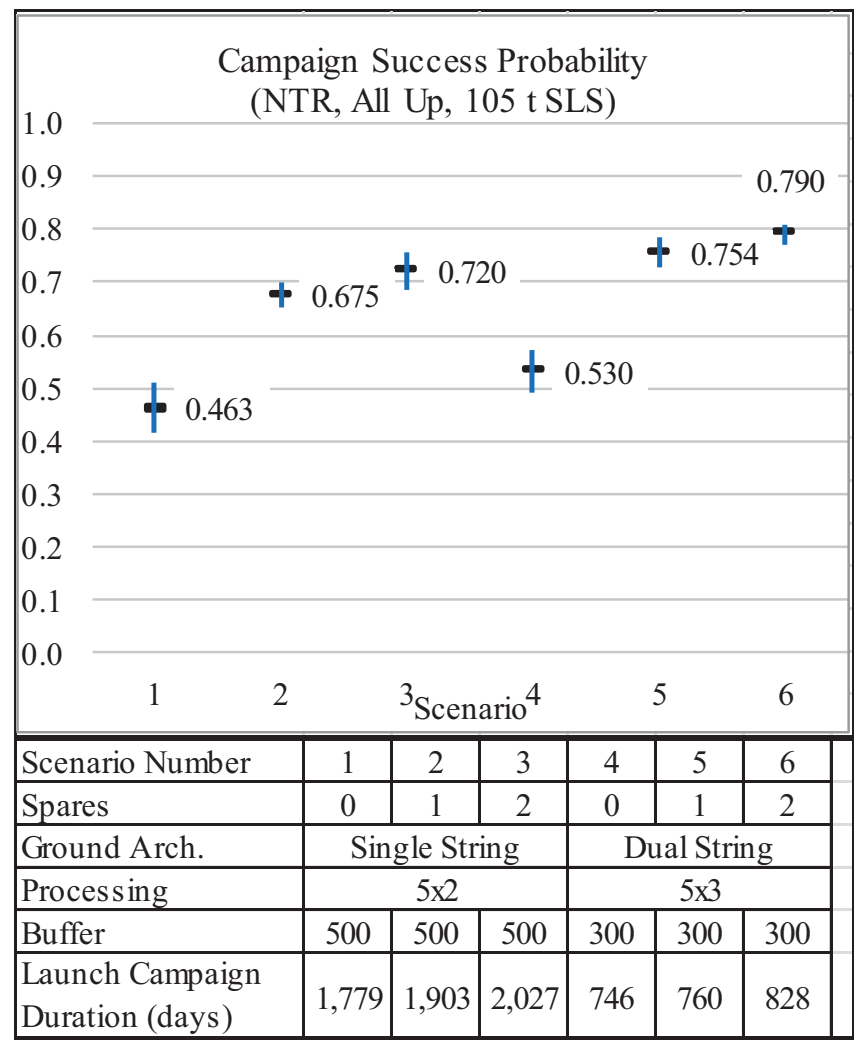

Figure 12 - Case 3 Summary Results

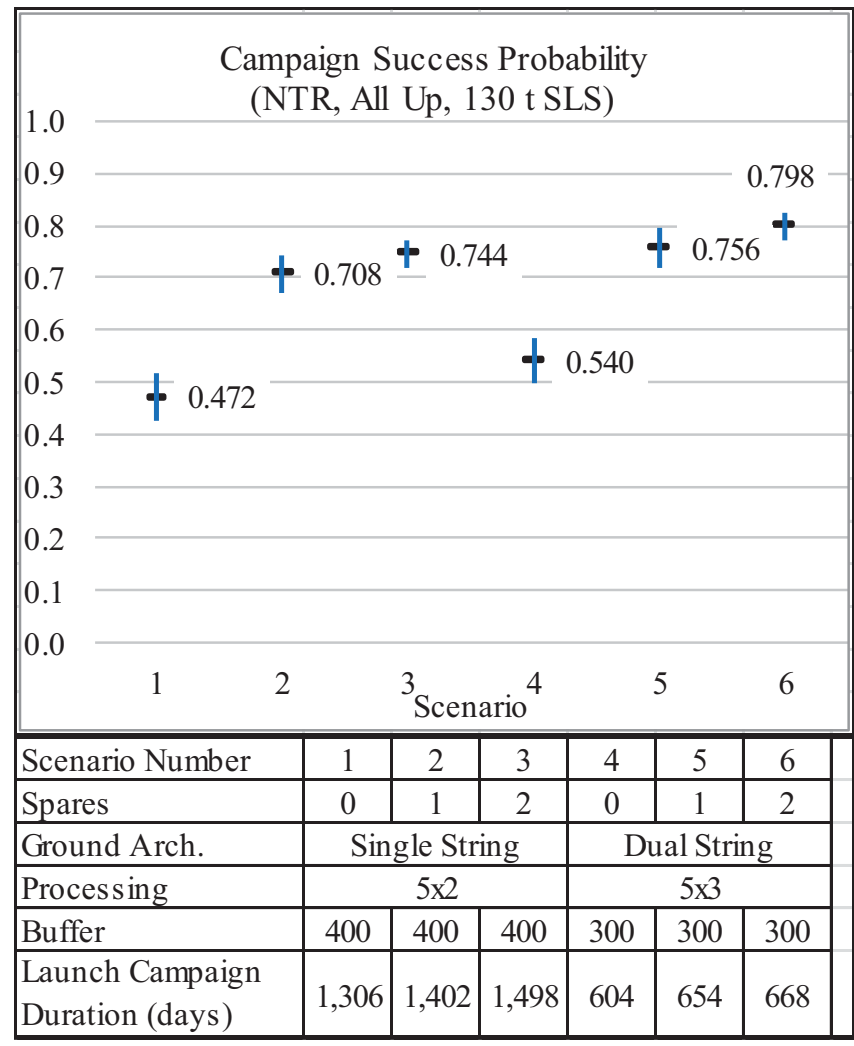

Figure 13 - Case 4 Summary Results 


\section{Detailed Results for Pre-Deployment of MTVs 1\&2}

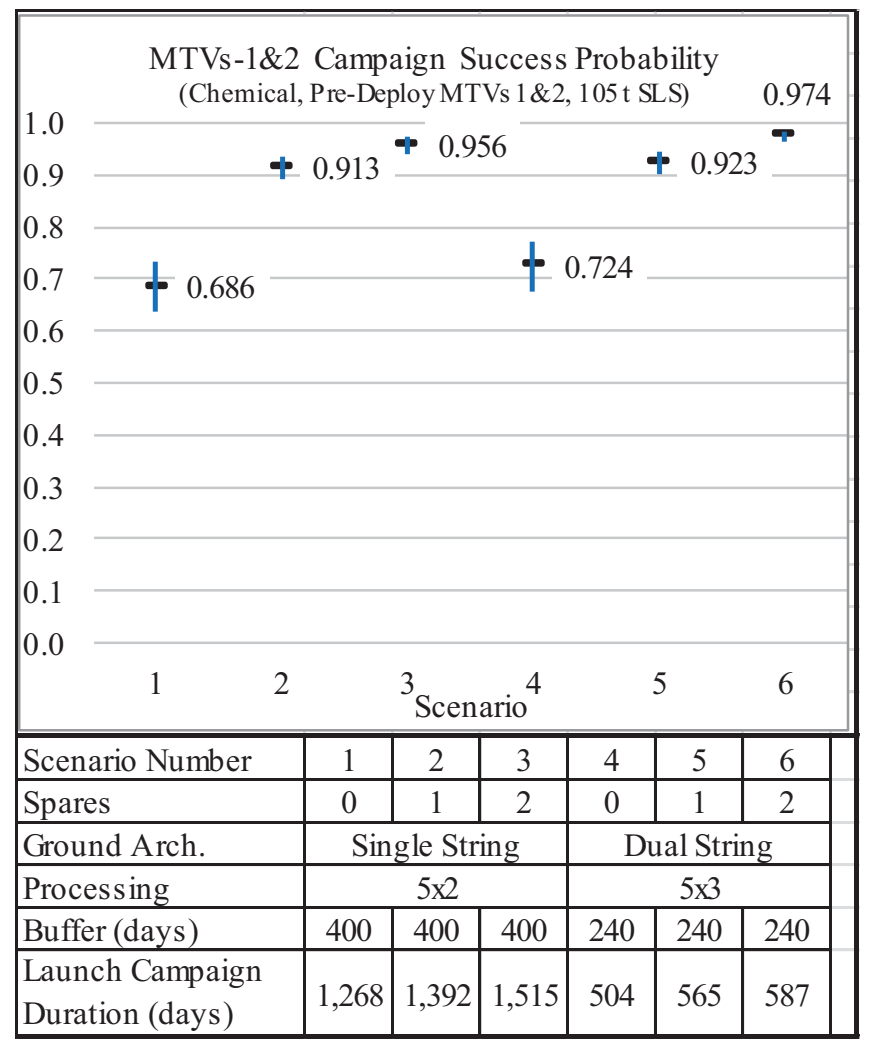

Figure 14 - Summary Results for Case 5 (Pre-Deploy, Chemical, 105 t SLS) Pre-Deployment of MTVs 1\&2

\begin{tabular}{|c|c|c|c|c|c|c|}
\hline \multicolumn{6}{|c|}{$\begin{array}{l}\text { MTVs-1\&2 Campaign Success Probability } \\
\text { (Chemical, Pre-Deploy MTVs } 1 \& 2,130 \text { t SLS) }\end{array}$} & \multirow{2}{*}{0.980} \\
\hline \multicolumn{3}{|c|}{$+0.932 \pm 0.941$} & \multicolumn{3}{|c|}{$\boldsymbol{\top} 0.959 \boldsymbol{\nabla}$} & \\
\hline+0.760 & \multicolumn{6}{|c|}{+0.789} \\
\hline \\
\hline \multicolumn{7}{|l|}{0.5} \\
\hline \multicolumn{7}{|l|}{0.4} \\
\hline \multicolumn{7}{|l|}{0.2} \\
\hline \multicolumn{7}{|l|}{0.1} \\
\hline 0.0 & 2 & \multicolumn{2}{|c|}{3 Scenario $^{4}$} & \multicolumn{2}{|c|}{5} & 6 \\
\hline Scenario Number & 1 & 2 & 3 & 4 & 5 & 6 \\
\hline Spares & 0 & 1 & 2 & 0 & 1 & 2 \\
\hline Ground Arch. & \multicolumn{3}{|c|}{ Single String } & \multicolumn{3}{|c|}{ Dual String } \\
\hline Processing & \multicolumn{3}{|c|}{$5 \times 2$} & \multicolumn{3}{|c|}{$5 \times 3$} \\
\hline Buffer (days) & 310 & 310 & 310 & 230 & 290 & 290 \\
\hline $\begin{array}{l}\text { Launch Campaign } \\
\text { Duration (days) }\end{array}$ & 931 & 1,055 & 1,178 & 411 & 532 & 554 \\
\hline
\end{tabular}

Figure 15 - Summary Results for Case 6 (Pre-Deploy, Chemical, 130 t SLS) Pre-Deployment of MTVs $1 \& 2$

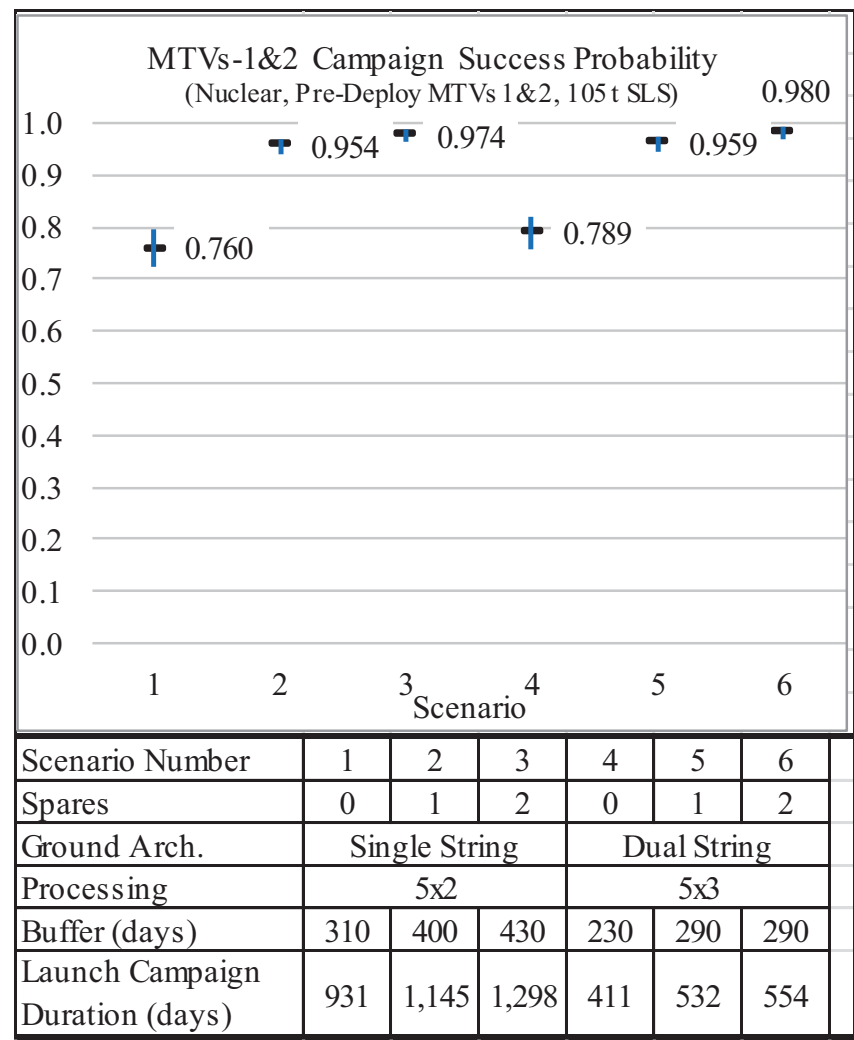

Figure 16 - Summary Results for Case 7 (Pre-Deploy NTR, 105 t SLS) Pre-Deployment of MTVs 1\&2

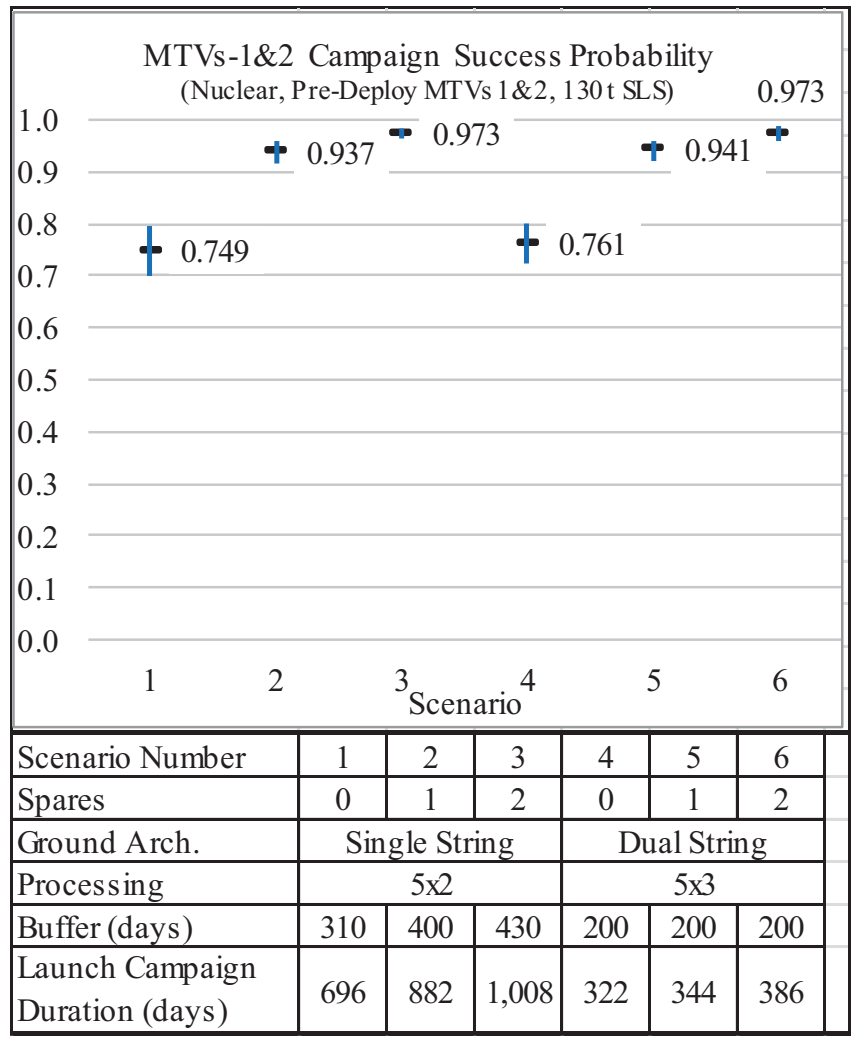

Figure 17 - Summary Results for Case 8 (Pre-Deploy NTR, 130 t SLS) Pre-Deployment of MTVs 1\&2 
Detailed Results for MTV-3 Campaigns

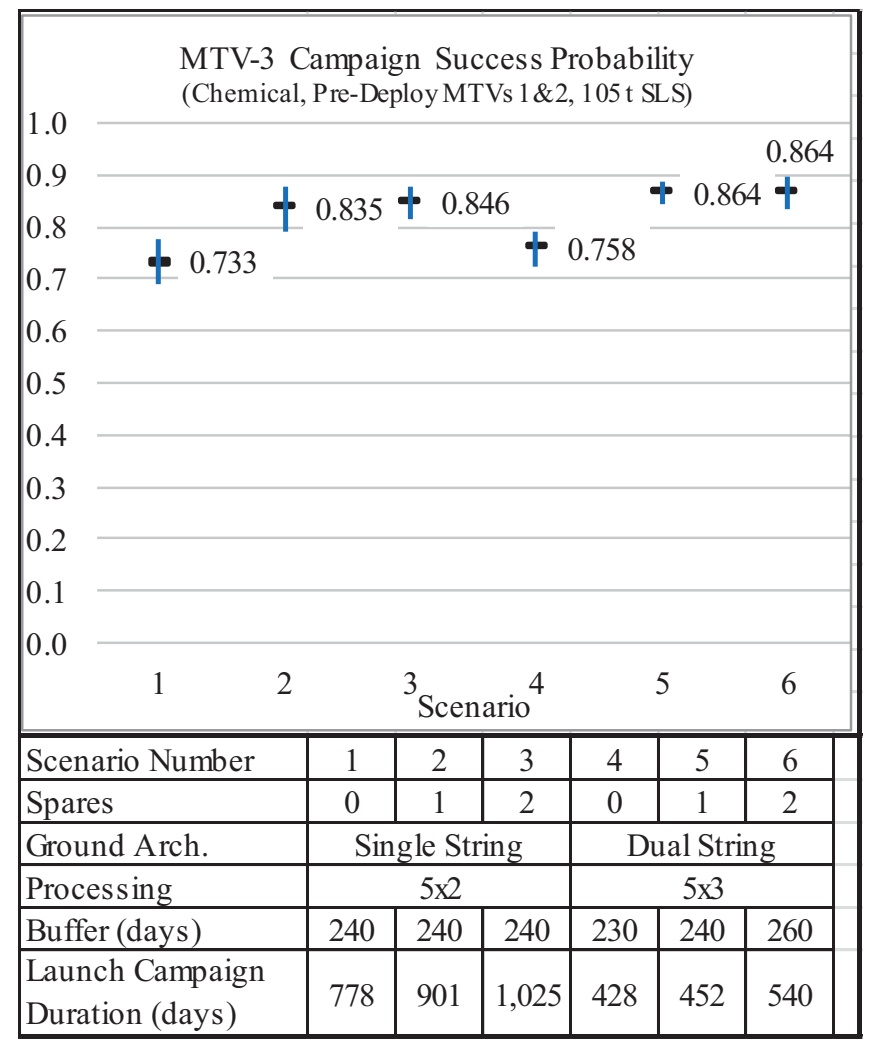

Figure 18- Summary Results for Case 5 (Pre-Deploy, Chemical, 105 t SLS) MTV-3 (Crew)

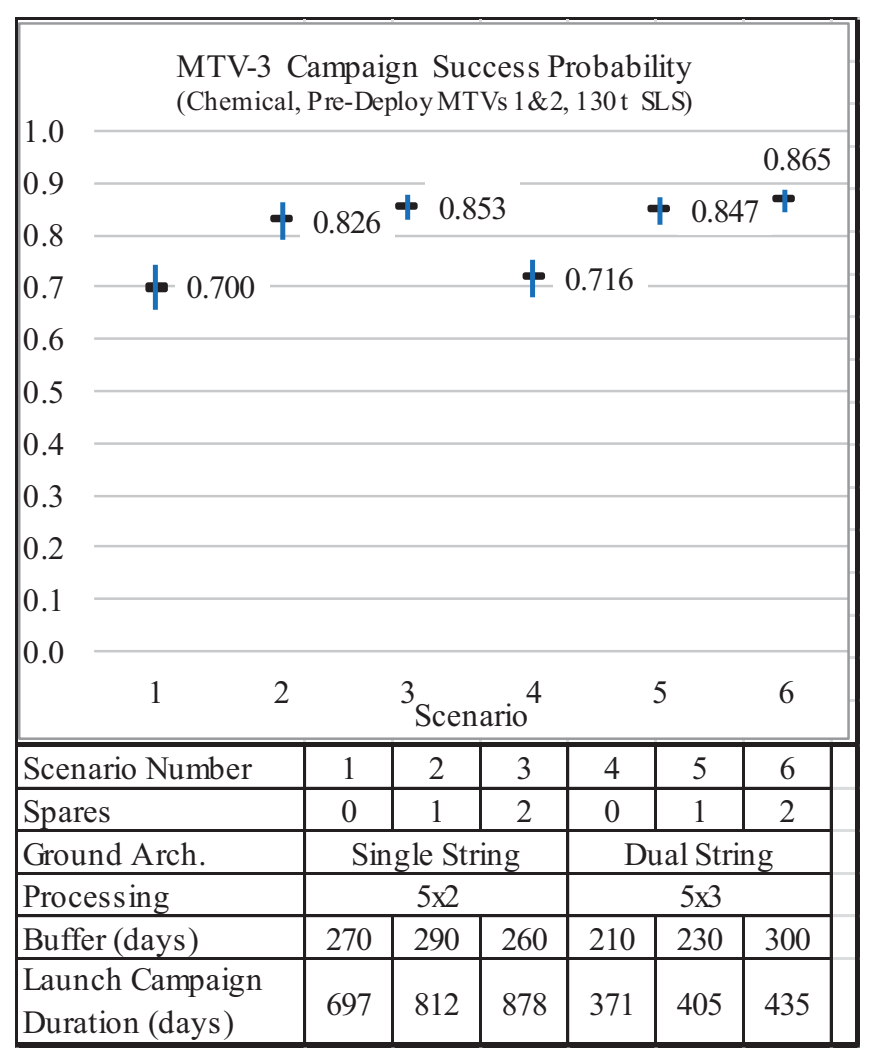

Figure 19-Summary Results for Case 6 (Pre-Deploy, Chemical, 130 t SLS) MTV-3 (Crew)

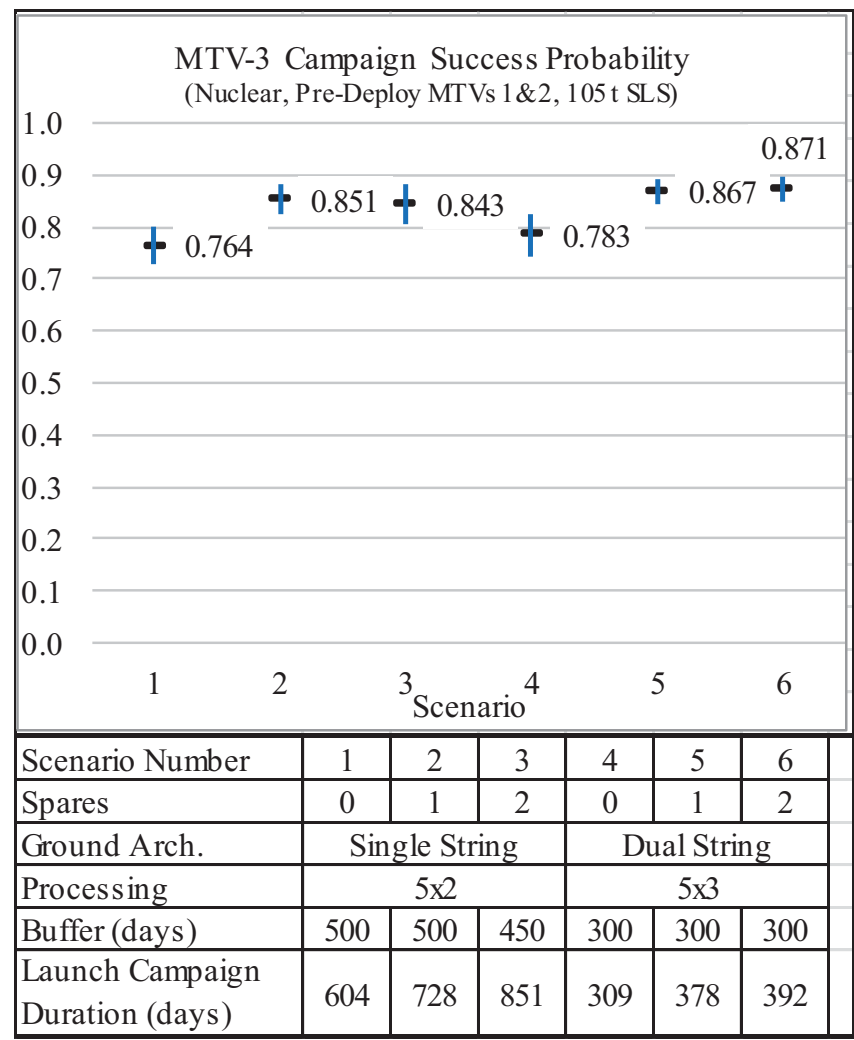

Figure 20 - Summary Results for Case 7 (Pre-Deploy, NTR, 105 t SLS) MTV-3 (Crew)

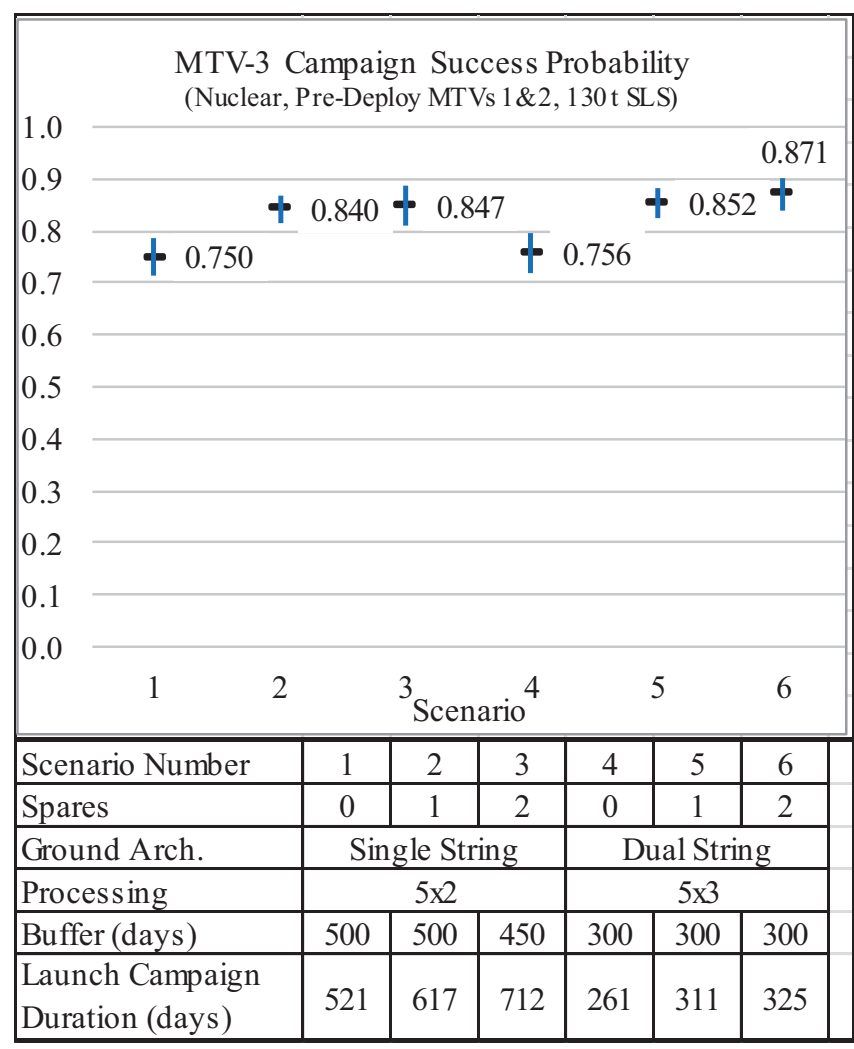

Figure 21- Summary Results for Case 8 (Pre-Deploy, NTR, 130 t SLS) MTV-3 (Crew) 
Detailed Results for Combined Pre-deployment of MTVs 1\&2 and MTV 3

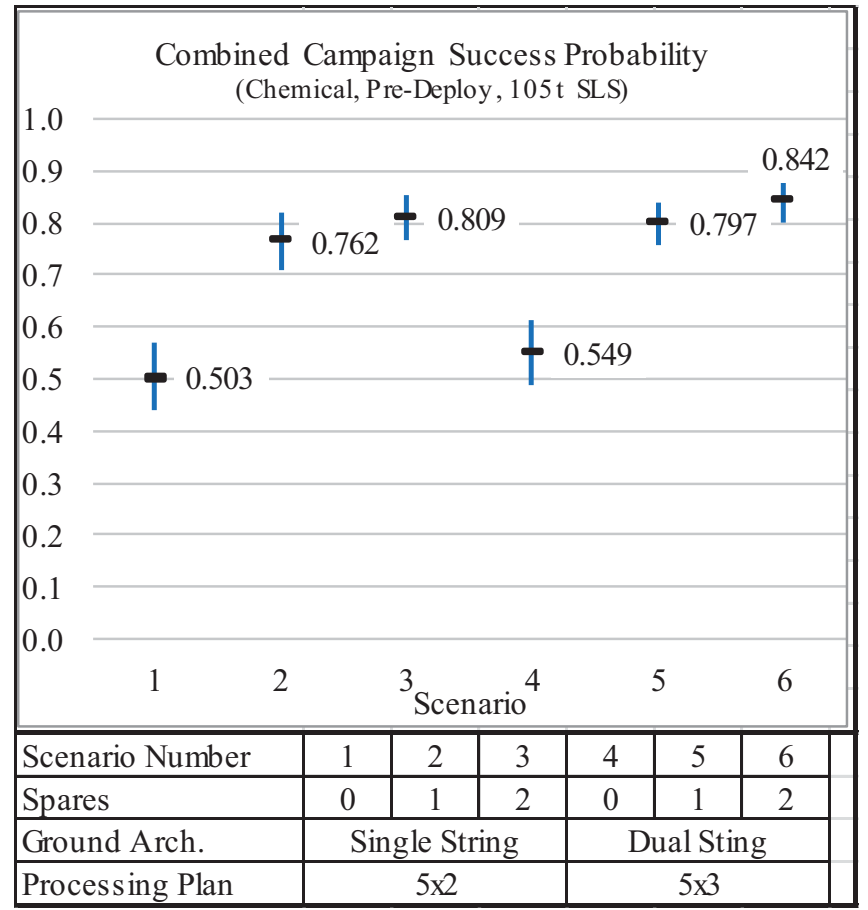

Figure 22 - Summary Results for Case 5 (Pre-Deploy, Chemical, 105 t SLS)

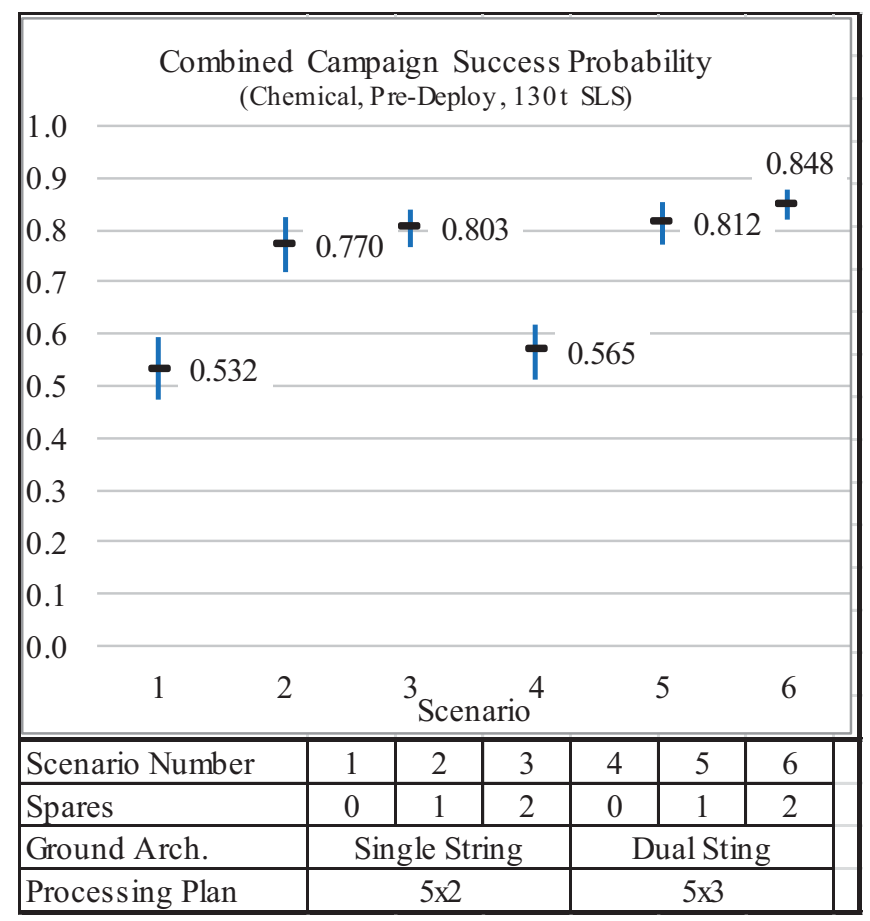

Figure 23-Summary Results for Case 6 (Pre-Deploy, Chemical, 130 t SLS)

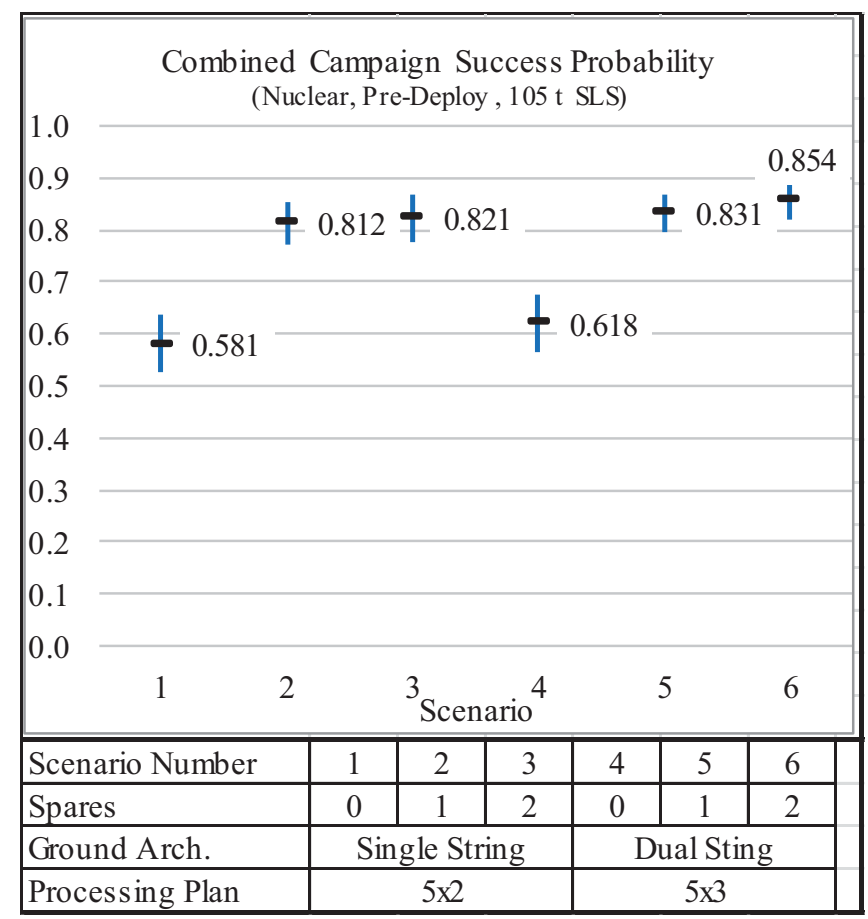

Figure 24- Summary Results for Case 7 (Pre-Deploy, NTR, 105 t SLS)

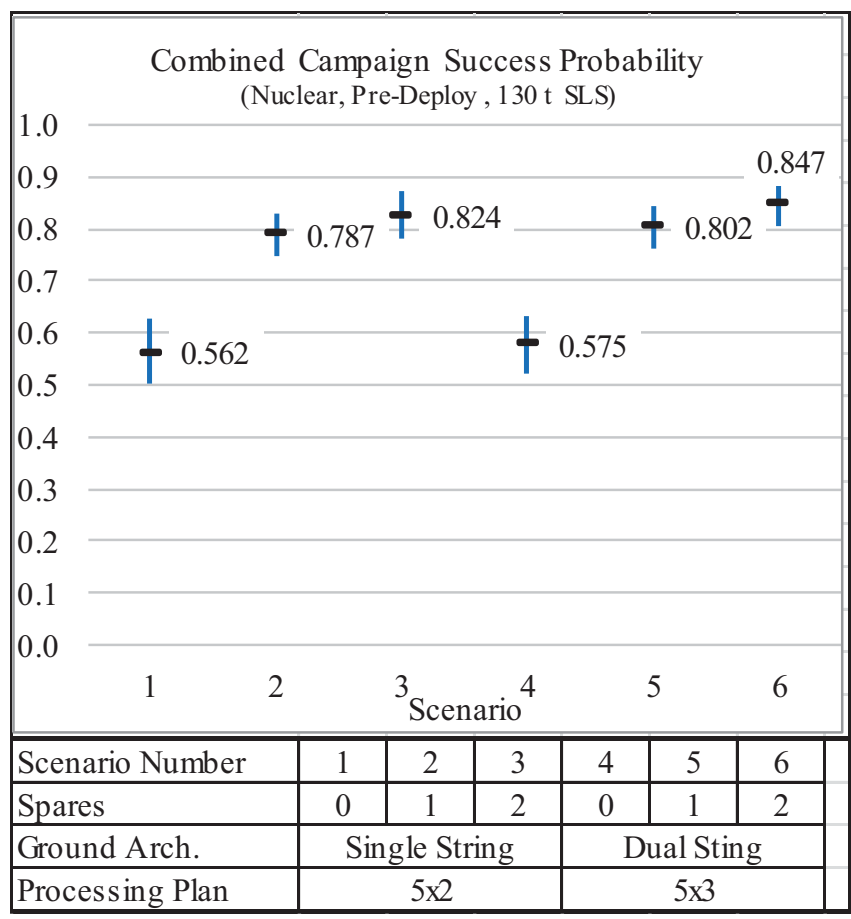

Figure 25- Summary Results for Case 8 (Pre-Deploy, NTR, 130 t SLS) 